\title{
Biodegradable Polymer Compounds Reinforced with Banana Fiber for the Production of Protective Bags for Banana Fruits in the Context of Circular Economy
}

\author{
Pablo Bordón ${ }^{1}\left[\right.$, Rubén Paz ${ }^{1, *} \mathbb{C}$, Carolina Peñalva ${ }^{2}$, Gisela Vega ${ }^{1}\left(\mathbb{D}\right.$, Mario Monzón ${ }^{1} \mathbb{D}$ and Lidia García ${ }^{3}$ \\ 1 Mechanical Engineering Department, Campus de Tafira Baja, Universidad de Las Palmas de Gran Canaria, \\ Edificio de Ingenierías, 35017 Las Palmas, Spain; pablo.bordon@ulpgc.es (P.B.); gisela.vega@ulpgc.es (G.V.); \\ mario.monzon@ulpgc.es (M.M.) \\ 2 AITIIP Centro Tecnológico, Polígono Industrial Empresarium C/Romero No 12, 50720 Zaragoza, Spain; \\ carolina.penalva@aitiip.com \\ 3 Tecnopackaging, Polígono Industrial Empresarium C/Romero No 12, 50720 Zaragoza, Spain; \\ lgarcia@tecnopackaging.com \\ * Correspondence: ruben.paz@ulpgc.es
}

check for updates

Citation: Bordón, P.; Paz, R.; Peñalva, C.; Vega, G.; Monzón, M.; García, L. Biodegradable Polymer Compounds Reinforced with Banana Fiber for the Production of Protective Bags for Banana Fruits in the Context of Circular Economy. Agronomy 2021, 11, 242. https://doi.org/10.3390/ agronomy11020242

Academic Editors: Fogarassy Csaba, Csaba Gyuricza and Richard Cruse Received: 9 January 2021

Accepted: 26 January 2021

Published: 28 January 2021

Publisher's Note: MDPI stays neutral with regard to jurisdictional claims in published maps and institutional affiliations.

Copyright: (c) 2021 by the authors. Licensee MDPI, Basel, Switzerland. This article is an open access article distributed under the terms and conditions of the Creative Commons Attribution (CC BY) license (https:/ / creativecommons.org/licenses/by/ $4.0 /)$.

\begin{abstract}
Bags used to protect and accelerate the ripening of bananas are a clear example of the environmental problem of packaging waste. Small pieces of these non-biodegradable bags are frequently disposed on the soil by accident (environmental conditions and poor handling during the harvest) and remain there for years. This work focuses on the development of protective biodegradable bags reinforced with banana fiber, obtained from waste of the banana plants, thus promoting a circular economy and a more environmentally friendly process. To achieve this, different bio-based composites were tested (processability) by compounding extrusion (biopolymer and banana fiber with different process steps) and blown film extrusion. The bags produced were tested in field and sequentially improved in three generations of biofilms. The results showed that the maximum processable fiber content was $5 \mathrm{wt} \%$. Additionally, the micronizing of the compounds was crucial to simplify the blown film extrusion and improve the smoothness of the bags (scratches avoidance on the banana surface). The final bags (Mater-Bi biopolymer, $5 \%$ combed and sieved banana fiber, and $2.5 \mathrm{wt} \% \mathrm{TiO}_{2}$ for ultraviolet light filtration), performed better than the conventional ones (faster maturing, i.e., earlier harvest, and easier handling) and fulfilled the biodegradability, composting and ecotoxicity test requirements.
\end{abstract}

Keywords: banana fiber; banana bunch protective bags; biopolymers; biodegradability; composting; blown film extrusion; compounding extrusion; circular economy

\section{Introduction}

The amount of waste generated is being reduced, despite efforts at the national and EU level. The European economic activities amount to 2.5 billion $t /$ year of waste [1]. A circular economy implies reducing this waste, but also could reduce the pressures on the environment, enhance the security of supply of raw materials, increase competitiveness and promote innovation, growth and jobs [2].

Agri-food products have relevant potential in the circular economy framework. The wastage generated during the supply chain, from production to consumption, could be used as the input of new products or production technologies instead of being landfilled or directly returned to the soil. Some of the proposed uses for agri-food residues are the production of fertilizers, generation of energy or as an input for bio-refineries. This last technology transforms enzymes, bacteria and biological materials into proteins, sugars, plastics, medicines or fuel [3].

The goals of reducing the packaging waste and revalorizing the agri-food wastage could be merged in the materials engineering sector, especially in the plastic industry, 
producing green materials. The bio-refinery contemplates several ways of combination, the biomass-based bioplastics and the agricultural-fiber-based polymeric matrices. Both replace synthetic materials while contributing to control environment problems [4].

There are several examples of the application of the circular economy from agricultural products. Suffo et al. showed the valorization of the Carbocal obtained in Spanish sugar beet factories, mixing it with thermoplastic matrices to obtain agro-composite. This application improves the mechanical properties of the compound and allows reducing the use of thermoplastics, for instance, in packaging products [4].

Another example is the one carried out in the wine industry, in Italy. The bioactive components of grape seeds (phenolic compounds, unsaturated fatty acids, vitamin E, carotenoids and phytosterols) are exploited before their biomass is used. This residue could be supplied to the food, pharmaceutical, cosmetic, biopolymeric materials and energy production industries [5].

Chiellini et al. proposed the incorporation of lignocellulosic fibers as organic fillers in the film matrix based on polyvinyl alcohol (PVA). Specifically, they proved that the incorporation of the fibers obtained from the sugar cane, apple and orange juice extraction in the preparation of the film, helps to obtain a non-toxic and naturally biodegradable product, which would contribute to providing organic matter to the soil in agricultural applications [6].

The use of natural fibers from plants or crop waste continues to arouse great interest in the scientific community. There is a wide range of natural fibers that have been characterized and tested as reinforcements in plastic components. For example, sisal fibers have been tested as reinforcement in a great variety of polymers such as polyurethane, polylactic acid (PLA), polypropylene (PP), polystyrene or polyester, showing relevant results in the improvement of the mechanical characteristics of the matrices, significantly affecting the previous treatments carried out to the fiber [7-12]. Abaca fiber also produces significant improvements in composites as hybrid reinforcement along with jute and glass in epoxy resins $[13,14]$, although the use of jute as reinforcement in polyester and glass hybrid epoxy resins has been more widespread due to its high availability and good mechanical properties [15-17]. Sisal, although with lower mechanical properties, has also been used with different manufacturing techniques and polymers in addition to polyesters, such as PP or acrylonitrile butadiene styrene (ABS) $[18,19]$. However, kenaf fiber is undoubtedly one of the highest produced and experimented, even at a commercial level, being tested with the greatest variety of polymers, hybrid composites and manufacturing techniques. It stands out especially for its use in reinforcing components in the automotive industry due to its high mechanical performance, similar to glass fiber [20] or in reinforcing components intended for shielding from electromagnetic interference [21]. Although less widespread, banana fiber $(\mathrm{BF})$ has a high specific tensile strength, even greater than sisal, hemp or jute, and similar to glass fiber [22]. Several investigations confirm the wide possibilities of this fiber as reinforcement, both in epoxy, PP, high-density polyethylene and ABS composites, among others [22-24].

Currently, bioplastics represent approximately $1 \%$ of the about 320 million t of plastic produced annually [25] in the European Union (data from 2015). According to the latest market data compiled by European Bioplastics in cooperation with the research institute nova-Institute, the global bioplastics production capacity is estimated to increase from around 2.05 million tonnes in 2017 to approximately 2.44 million tonnes in 2022. By 2020 , biodegradable plastics will represent $18 \%$ of bioplastics production and biobased, non-biodegradable plastics will rise to $82 \%$ [26].

There is a wide variety of bioplastics depending on the raw material. Table 1 shows some examples of bioplastics and the natural source [27]. 
Table 1. Example of bioplastics.

\begin{tabular}{cc}
\hline Type of Bioplastic & Primary Feedstock \\
\hline Thermoplastic starch (TPS) & Starch \\
Plastarch material (PSM) & Starch \\
Starch/polycaprolactone (or polyvinyl acetate) mix & Starch/petroleum \\
Polyhydroxyalkanoates (PHA) & Starch sugars \\
Cellulose acetate & Starch sugars \\
Lignin & Wood, cotton or hemp cellulose \\
Bio Polyethylene & Wood (lignin) \\
Bio Polyurethane & Sugarcane-derived bioethanol \\
BioPBS (Polybutylene succinate) & Soya beans \\
\end{tabular}

The environmental problems of plastic film for packaging have brought new policies in the world to limit the production and use of this product. In the European Union, the European parliament voted in favor of reducing the consumption of plastic bags up to $80 \%$ in 2019 compared to 2010 (in 2010, approximately 100 billion plastic carrier bags were placed on the EU market [28]). Additionally, new EU legislations are coming out regarding the inclusion of recycled content in the packaging sector. The major food companies are beginning to monopolize the supply of recycled content and, as a consequence, small companies will probably move away from synthetic to biobased polymers. Bioplastics are still relatively expensive if compared to plastics from oil, but their use in the industry of film for packaging is growing because of the positive effects on the environment, because of the renewable natural source and, in many cases, the biodegradability (chemical disintegration into $\mathrm{CO}_{2}$, water and biomass, with the help of microorganisms under natural conditions) and even the compostability (biodegradation under specific conditions also meeting certain criteria in terms of speed and composition/quality of the resulting compost). The lack of mechanical properties in some biomaterials can be balanced by adding different kinds of reinforcements that should be naturally-based to keep the bio concept.

Many research works have been carried out to develop composites of biofilm. X. Wang et al. [29] tested a nanocomposite film of PLA and nanocrystalline cellulose (NCC $4 \mathrm{wt} \%$ ), by pouring a thin layer $(0.08 \mathrm{~mm})$ onto a flat surface. They observed a significant increase of tensile strength and tensile modulus of $38.1 \%$ and $8.91 \%$, respectively. Other authors [30] used the same reinforcement based on NCC, extracted from rice straw, by the solvent casting of polyvinyl alcohol (PVA)/ chitosan (CS) with up to $5 \mathrm{wt} \%$ NCC. With the addition of $5 \mathrm{wt} \%$ NCC, the tensile strength of PVA/CS film increased from $56.12 \mathrm{MPa}$ to $98.15 \mathrm{MPa}$, and the elastic modulus from $892 \mathrm{MPa}$ to $1764 \mathrm{MPa}$. Another approach [31], with bigger size of the reinforcement, was carried out by compression molding of a film formed by a blend of PLA/ethylene-vinyl acetate-glycidyl methacrylate random copolymer (NPG) and particles of lignin (LMP, up to $1 \mathrm{wt} \%$ ), with good vapor barrier properties, suitable for food packaging. The inclusion of LMP produced a significant increase of the toughness of PLA/NPG blend, up to $236 \%$, with a slow decrease of tensile strength and elastic modulus. Varghese et al. [32] developed a novel composite film based on Poly(3-hydroxybutyrate-co3-hydroxyvalerate) (PHBV) and the addition of natural fibers from the Ceiba pentandra (CP) tree. They prepared films with up to $20 \mathrm{wt} \%$ of $\mathrm{CP}$ fiber by spreading the solution in a glass plate. The high level of fiber agglomeration for $20 \mathrm{wt} \% \mathrm{CP}$ content reduced the tensile strength, being the best result at $5 \mathrm{wt} \%$, increasing this parameter from 22 to $26 \mathrm{MPa}$. Additionally, M.A. Berthet et al. [33] used PHBV processed by compounding extrusion and compression molding, with different content and particle size of milled wheat straw fibers. The best results, in terms of maximum filler content, were when the size of fiber was lower, due to better homogeneity and wetting of fibers by the polymer. Nevertheless, to produce biofilm by film blowing reinforced with natural fiber becomes more difficult mainly when the size of the reinforcement is not at the nanoscale. This is mainly due to the stretching process of the film during the blowing, breaking the weakest points of the fiber-matrix 
interphase. For instance, Cunha et al. [34] compounded PHBV with beer spent grain fibers (BSGF) to produce film by film blowing. $75 \mathrm{wt} \%$ of the milled fibers had an average size of the order of $30 \mu \mathrm{m}$ and $5 \%$ were larger than $120 \mu \mathrm{m}$. The film thicknesses were between 40 and $150 \mu \mathrm{m}$ but it was observed several fractures of the film containing $5 \mathrm{wt} \%$ of BSGF. This film turned out to be less stiff and crystalline than PHBV films and exhibited increased permeability to $\mathrm{O}_{2}$. Kharrat et al. [35] prepared compounding of 1.2 and $5 \mathrm{wt} \%$ of date palm leaves fiber (DPLF) microparticles, as filler, and PLA to make film blowing. They observed that the optimal amount of filler was $1 \mathrm{wt} \%$, increasing the tensile strength and tensile modulus, while $5 \mathrm{wt} \%$ clearly worsened the mechanical properties due to the loss of film crystallinity and the poor adhesion between the fillers and the matrix.

Only a few references have been found using banana fiber as reinforcement for films, but none of them for film blowing extrusion. For example, by the process of solution casting, Srivastava [36] developed a composite of polyvinyl alcohol (PVA) with microparticles of banana fiber, with three different size groups $(<53,53-75$ and $75-90 \mu \mathrm{m})$, and two different treatments (alkali with Sodium hydroxide and acid treatment with Sulfuric acid). In terms of tensile strength, the best results were with alkali treatment $(7.5 \% w / v$ concentration) at $20 \mathrm{wt} \%$ of fiber loading.

Regarding the banana production, the Canary Islands (Spain) are the main producer of bananas in Europe (406,225 $\mathrm{t}$ in 2019 according to the Association of Banana Producers' Organisations in the Canary Islands, ASPROCAN [37]). During the cultivation, farmers use protection bags (sleeves) to accelerate the ripening process and protect the bananas until their final harvest. Small pieces of these bags, commonly made of non-biocompostable low-density polyethylene (LDPE), are frequently and accidentally disposed on the soil of the banana plantations due to environmental conditions and poor handling during the harvest. Considering the previous context and this environmental problem in the banana plantations, this work focuses on the development of protections bags for banana fruits, based on biodegradable polymers reinforced with banana fiber (obtained from waste of banana plants) by film blowing extrusion. Therefore, the goal is to replace these nonbiodegradable bags by bio-based and biodegradable ones, reinforced with banana fiber, thus promoting a circular economy and a more environmentally friendly process.

\section{Materials and Methods}

This section details the materials used (biomaterials/additives and banana fiber), the manufacturing processes (compounding extrusion and film blowing) and the characterizations carried out (mechanical tests with mold injected specimens, validation in field of the bags, composting and biodegradability assays). Several tests and three biofilm generations were carried out to select the best biopolymer and process steps/parameters for this application (protective bags for bananas). These tests (hereinafter, "preliminary tests") started before the production of the 1st generation of biofilm but continued after that generation. The results of the preliminary tests and biofilm generations were used to sequentially improve the final product (3rd biofilm generation, which was validated in field and under biodegradability tests). Figure 1 shows a scheme of the methods used. 


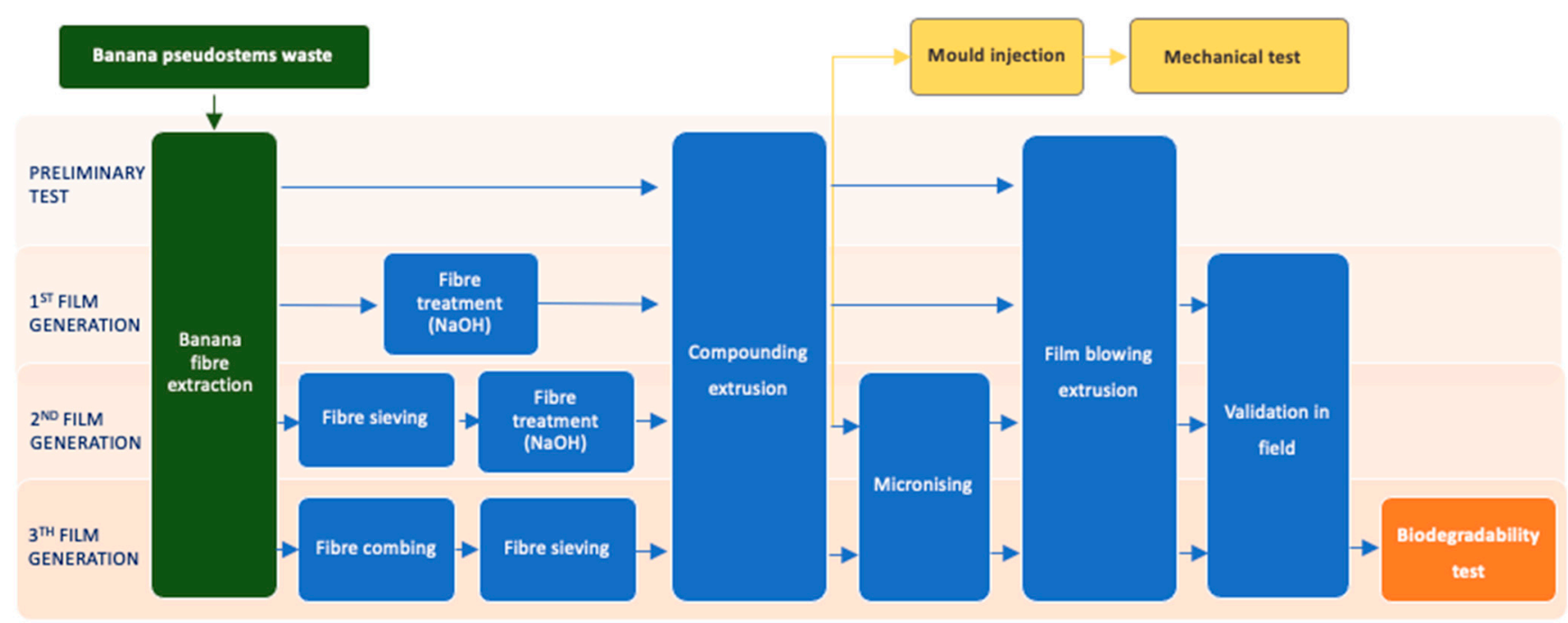

Figure 1. Fiber treatment and manufacturing process diagram.

\subsection{Biomaterials and Additives}

Three different formulations of compounds have been developed and sequentially improved to obtain reinforced biofilms generations, all of them being food contact approved, biobased, biodegradable and processable.

The 1st generation allowed the assessment of the selected biopolymeric matrices (Table 2). For the 2nd generation, one of the biomatrices (PLA 4032D) was discarded due to the loss of physical integrity of banana sleeves. This polymer was replaced by PLA PLSF 101 B, also from Natureplast, as it had a greater flexibility. Moreover, the PHA Danimer 21906 was discarded due to its higher price and non-European origin (important disadvantage in the context of the circular economy, due to the long shipping needed). The results of the 2nd generation of biofilms allowed for a 3rd and final review of materials, where the BioPBS FD92PM was discarded due to its higher price and lower performance.

Table 2. Polymers selected for each film generation.

\begin{tabular}{ccc}
\hline 1st Film Generation & 2nd Film Generation & 3rd Film Generation \\
\hline $\begin{array}{c}\text { PLA Ingeo Biopolymer 4032 D } \\
\text { (Natureworks) }\end{array}$ & $\begin{array}{c}\text { PLA PLSF 101 B } \\
\text { (Natureplast) }\end{array}$ & - \\
\hline $\begin{array}{c}\text { PHA blend Danimer 21906 } \\
\text { (Danimer) }\end{array}$ & - & $\begin{array}{c}\text { Starch and PCL Mater-Bi } \\
\text { EF04P } \\
\text { (Novamont) }\end{array}$ \\
\hline $\begin{array}{c}\text { Starch and PCL Mater-Bi EF04P } \\
\text { (Novamont) }\end{array}$ & $\begin{array}{c}\text { Starch and PCL Mater-Bi } \\
\text { EF04P } \\
\text { (Novamont) }\end{array}$ & - \\
\hline $\begin{array}{c}\text { BioPBS FD92PM } \\
\text { Performance Polymers) }\end{array}$ & BioPBS FD92PM &
\end{tabular}

For the first generation of biofilms, some additives were added. $\mathrm{TiO}_{2}$ was used to filter ultraviolet (UV) light to improve bananas coloring and protect the polymer from UV degradation (high refractive index) [38]. According to the literature [39], concentrations of $3 \mathrm{wt} \% \mathrm{TiO}_{2}$ were sufficient to act as $\mathrm{UV}$ blocker for fruit bagging with different biopolymers. This percentage was used for the 1st generation.

Glyplast 206/3NL by Condensia (poliadipate plasticizer listed in 1/2011EC, biodegradable at $85 \%$ ) was used only for PLA compound at $7 \mathrm{wt} \%$. This plasticizer is a high molecular weight ester with low volatility and migration, high flash point, good thermal stability and good compatibility with PLA. 
In the 2 nd and $3 \mathrm{rd}$ generations, $2.5 \mathrm{wt} \% \mathrm{TiO}_{2}$ was considered enough according to the results of other research done by the authors [39]. A different PLA matrix was also used (more flexible to avoid breaks in the bags), in this case without plasticizer since PLSF $101 \mathrm{~B}$ already includes it and is flexible enough.

\subsection{Banana Fiber}

Leaves of canary banana pseudostems (waste after harvesting the bananas) were processed in a pilot plant developed by the University of Las Palmas de Gran Canaria [40] to obtain clean and chopped banana fiber [41]. According to previous works carried out by the University of Las Palmas de Gran Canaria, the banana fiber of the Canary Islands has an average diameter of $0.180 \mathrm{~mm}$ [42], a tensile modulus of $43 \mathrm{GPa}$ and tensile strength of $891 \mathrm{MPa}$ [43] (note that these average values may vary due to the inherent variability of natural fibers).

Alkaline treatment was applied to the 1st and 2nd fiber generations to improve its surface and interaction with the polymer matrices [43,44]. A bubble column reactor with suspended solids was used to produce batches of treated chopped fiber [44] with a $\mathrm{NaOH} 1 \mathrm{~N}$ solution. Batches of $2 \mathrm{~kg}$ fiber were treated at room temperature for $1 \mathrm{~h}$. Subsequently, the wet treated fiber was centrifuged at $1000 \mathrm{rpm}$ and dried by infrared lamps in a continuous rotation system. After the drying process, the moisture content of the treated fiber was approximately $12 \mathrm{wt} \%$.

A preliminary processability test by compounding extrusion and film blowing was performed with untreated banana fiber ( 3 and $5 \mathrm{~mm}$ length, to analyze the most suitable length for processing) and PLA without additives. After this preliminary test, the length of the fiber was reduced to $2 \mathrm{~mm}$ to improve the processability. Then, a design of experiments was planned to test the remaining materials. Treated $(1 \mathrm{~N} \mathrm{NaOH})$ banana fiber was processed for the 1 st film generation. For the 2 nd and 3 rd film generations, the fiber was sieved after the cutting process in a developed rotational sieving machine [40]. This step was included to remove long fibers that are not properly cut in the chopping subsystem (which hinder the compounding and film blowing extrusion) and to eliminate impurities that are not perfectly removed in the fiber extraction machine (which degrade on the compounding extrusion and film-blowing processes, worsening the appearance and mechanical properties). Apart from this, compounding pellets of the 2nd and 3rd generations were also micronized to facilitate the film blowing and to improve the performance of the bags. Moreover, during the fiber extraction for the 2nd film generation, long fibers were manually combed and then cut into $2 \mathrm{~mm}$ length and used for characterization without $\mathrm{NaOH}$ treatment. The purpose of this test was to assess the effect of the combing step on the purity/cleanliness of the fiber (the cleaner the fiber, the lower degradation during the processing and the better the adhesion to the matrix). The results (included in the preliminary tests, Section 3.1.2, for the sake of clarity) showed that the $\mathrm{NaOH}$ treatment could be replaced by the combing step, which is more sustainable and cheaper. For this reason, in the 3rd film generation, the fiber used was untreated and combed. In summary, the fibers used were:

- $\quad$ Preliminary tests: untreated banana fiber ( 3 and $5 \mathrm{~mm}$ length), and also $2 \mathrm{~mm}$ combed banana fiber (obtained during the extraction of the 2 nd film generation)

- $\quad$ 1st film generation: treated banana fiber $(1 \mathrm{~N} \mathrm{NaOH})(2 \mathrm{~mm}$ length)

- $\quad$ 2nd film generation: treated and sieved banana fiber ( $1 \mathrm{~N} \mathrm{NaOH})$ (2 mm length) (micronized compounding)

- $\quad 3 r d$ film generation: untreated, combed and sieved banana fiber (2 mm length) (micronized compounding)

\subsection{Compounding Extrusion}

Compounding extrusion was performed in a Coperion ZSK 26 semi-industrial extruder (Coperion $\mathrm{GmbH}$, Stuttgart, Germany) with a twin screw and throughput rates up to $80 \mathrm{~kg} / \mathrm{h}$. The biopolymer was previously dried in a Moretto Xdry air T dehumidifier 
(Moretto S.p.A., Massanzago, PD, Italy) for $4 \mathrm{~h}$ at $60^{\circ} \mathrm{C}$ to reduce the moisture content. A Brabender DSR28 single screw feeder (Brabender GmbH \& Co. KG, Duisburg, Germany) with stirring agitator was used.

A preliminary compounding extrusion test was carried out to determine the maximum banana fiber (BF) content that could be added to the formulations for future pilot line production. This preliminary test was performed with untreated banana fiber ( 3 and $5 \mathrm{~mm}$ length) and PLA matrix without additives. Table 3 shows the extrusion parameters of this preliminary compounding.

Table 3. Compounding extrusion process parameters for the preliminary tests.

\begin{tabular}{cccccc}
\hline Compounding & $\begin{array}{c}\text { Flow Rate } \\
\text { PLA (kg/h) }\end{array}$ & $\begin{array}{c}\text { Flow Rate BF } \\
\mathbf{( k g / h )}\end{array}$ & $\begin{array}{c}\text { Extruder } \\
\text { Temperature } \\
\text { Range }\left({ }^{\circ} \mathbf{C}\right)\end{array}$ & $\begin{array}{c}\text { Extruder } \\
\text { Pressure } \\
\text { (bar) }\end{array}$ & $\begin{array}{c}\text { Pelletiser } \\
\text { Speed (rpm) }\end{array}$ \\
\hline PLA + 3 mm BF (10\%) & 4.5 & 0.5 & $175-180$ & 29 & 20 \\
PLA + 5 mm BF (5\%) & 5.1 & 0.3 & $175-180$ & 4 & 20 \\
\hline
\end{tabular}

Apart from the optimal banana fiber percentage (5 wt \%, depicted in Section 3.1.1), different banana fiber percentages and biopolymers were extruder to later produce mold injected specimens for characterization. Table 4 summarizes the biopolymer matrix and fiber content used.

Table 4. Compounding formulations for characterization (mold injected samples).

\begin{tabular}{|c|c|c|c|c|c|}
\hline \multirow[b]{2}{*}{ Polymer Matrix } & \multicolumn{5}{|c|}{ Percentage of Different Types of Fibers in the Compounding } \\
\hline & $\begin{array}{c}\text { Untreated } \\
\text { Banana Fiber } \\
(3 \mathrm{~mm})\end{array}$ & $\begin{array}{c}\text { Untreated } \\
\text { Banana Fiber } \\
(5 \mathrm{~mm})\end{array}$ & $\begin{array}{l}\text { Untreated and } \\
\text { Combed Banana } \\
\text { Fiber }(2 \mathrm{~mm})\end{array}$ & $\begin{array}{c}\text { 1st Gen Treated } \\
\text { Banana Fiber } \\
(2 \mathrm{~mm})\end{array}$ & $\begin{array}{c}\text { 2nd Gen Treated } \\
\text { Banana Fiber } \\
\text { (Micronised) }\end{array}$ \\
\hline PLA Ingeo 4032D & $0,1,2.5,5,10 \%$ & $0,1,2.5,5 \%$ & $0,2.5,5,7.5,10 \%$ & $0,2.5,5,7.5,10 \%$ & - \\
\hline Danimer 21906 & - & - & - & $0,1,2.5,5 \%$ & - \\
\hline Mater-Bi EF04P & - & - & - & $0,2.5,5,10 \%$ & $0,2.5,5,7.5,10 \%$ \\
\hline BioPBS FD92PM & - & - & - & $0,2.5,5 \%$ & $0,2.5,5,7.5,10 \%$ \\
\hline PLA PLSF101 B & - & - & - & - & $0,2.5,5,7.5,10 \%$ \\
\hline
\end{tabular}

Taking into account the results of the previous preliminary tests and characterization, Table 5 shows the final combination of materials for the compounding extrusion and subsequent film blowing of the three generations of biofilms.

Table 5. Compounding for each generation of biofilms.

\begin{tabular}{ccc}
\hline 1st Film Generation & 2nd Film Generation & 3rd Film Generation \\
\hline $\mathrm{PLA}+7 \% \mathrm{GP}{ }^{1}+3 \% \mathrm{TiO}_{2}+5 \% \mathrm{BF}$ & $\mathrm{PLA} \mathrm{PLSF}+2.5 \% \mathrm{TiO}_{2}+5 \% \mathrm{BF}$ & - \\
Danimer $+3 \% \mathrm{TiO}_{2}+5 \% \mathrm{BF}$ & - & - \\
Mater- $\mathrm{Bi}+3 \% \mathrm{TiO}_{2}+5 \% \mathrm{BF}$ & Mater-Bi $+2.5 \% \mathrm{TiO}_{2}+5 \% \mathrm{BF}$ & $\mathrm{Mater}-\mathrm{Bi}+2.5 \% \mathrm{TiO}_{2}+5 \% \mathrm{BF}$ \\
BioPBS $+3 \% \mathrm{TiO}_{2}+5 \% \mathrm{BF}$ & $\mathrm{BioPBS}+2.5 \% \mathrm{TiO}_{2}+5 \% \mathrm{BF}$ & - \\
\hline${ }^{1}$ Glyplast plasticizer. &
\end{tabular}

In the 2nd and 3rd film generations, the extruded formulations were micronized by cryogenic grinding, cooling the material and then reducing it to small particle sizes to improve the film blowing process. The target particle size was $500 \mu \mathrm{m}$, low enough to avoid holes when it is blown, but long enough to maintain its reinforcing effect. Table 6 shows the particle size distribution of the micronized formulations (2nd and 3rd generations). Mater-Bi micronized particles were the smallest, followed by BioPBS and PLA. This affects the subsequent polymer processing, since larger particle requires higher temperatures. 
Table 6. Particle size distribution (ISO 3310-1).

\begin{tabular}{cccc}
\hline Particle Size & PLA Compound & Mater-Bi Compound & BioPBS Compound \\
\hline$>500$ & $0.00 \%$ & $0.00 \%$ & $0.00 \%$ \\
$425-500$ & $36.08 \%$ & $10.72 \%$ & $19.81 \%$ \\
$300-425$ & $34.23 \%$ & $24.12 \%$ & $22.07 \%$ \\
$150-300$ & $24.88 \%$ & $43.21 \%$ & $40.99 \%$ \\
$<4.81$ & $4.81 \%$ & $21.95 \%$ & $18.03 \%$ \\
\hline
\end{tabular}

The integration and dispersion of the fiber in the polymer was improved by adjusting the processing parameters (e.g., homogenization rate and mixing time).

\subsection{Mechanical Characterization}

Several formulations were extruded (compounding extrusion) using virgin PLA with additives (Table 4) and mold injected to produce tensile test specimens (ISO 527-2:2012). During the mold injection of the samples, the fiber started to burn (untreated fiber, which degrades more easily), obtaining darker specimens in the consecutive cycles. For this reason, the temperature was decreased as much as possible to minimize this effect. The final mold injection was carried out with a temperature range of the screw between 165 and $185^{\circ} \mathrm{C}$, a mold injection pressure of $40 \mathrm{bar}, 10 \mathrm{~s}$ of holding pressure and a cooling time of $6 \mathrm{~s}$, in a JSW J85 injection molding unit (Japan Steel Works, Ltd., Tokyo, Japan). The objective of the mechanical characterization was to assess the improvement of the mechanical properties due to the fiber reinforcement effect. A subsequent SEM characterization was carried out in a Hitachi S3400N equipment (Hitachi, Ltd., Tokyo, Japan) to assess the fiber dispersion and provide feedback for the compounding extrusion process.

The mechanical tests were performed in a Zwick-Roell 10kN ProLine tensile machine (Zwick Roell Group, Munich, Germany), with constant crosshead speed, according to the standard ISO 527-2:2012 for conducting the tensile test and determining the elastic modulus.

Apart from the mold injected samples with PLA, which were used as a reference to analyze the mechanical reinforcement effect of the fiber, more mold injected samples and mechanical tests were applied to the formulations depicted in Table 4 . The holding pressure time (10 s) and cooling time (6 s) were maintained as in PLA compounds. However, the temperatures in the screw and mold injection pressure were adjusted for each biopolymer matrix. In the case of Danimer, the temperature range was $130-170{ }^{\circ} \mathrm{C}$ and the mold injection pressure 55 bar. In the case of Mater-Bi compounds, the temperature range was $140-155{ }^{\circ} \mathrm{C}$ and the mold injection pressure 90 bar. For BioPBS, the temperature was $130-150^{\circ} \mathrm{C}$ and the pressure 56 bar.

\subsection{Film Blowing Extrusion}

Film blowing extrusion was performed in a LF-400 COEX unit with a Labtech LE 25 extruder (Labtech Engineering Company Ltd., Samutprakarn, Thailand), after drying the material in a Moretto Xdry air T (Moretto S.p.A., Massanzago, Padua, Italy) for $4 \mathrm{~h}$ at $60^{\circ} \mathrm{C}$.

The design of the current LDPE banana sleeves used by farmers was maintained. These bags have approximately $1700 \mathrm{~mm}$ length and $800 \mathrm{~mm}$ width and are not sealed on the bottom nor the top. They are placed covering the banana bunch and tied to the stem of the banana bunch on the top. The bottom side is not usually tied to the stem to allow the proper disposal of condensation liquids and aeration, especially in periods of high temperatures. Moreover, bags include holes to improve this aeration. In this case, $6 \mathrm{~mm}$ diameter perforations were made on the bags every $100 \mathrm{~mm}$ length and width.

A preliminary film blowing test was carried out with virgin PLA pellets and composite of PLA with banana fiber to optimize the process parameters, trying to stabilize the bubble and lower the processing temperature as much as possible. 


\subsection{Validation in Field}

The developed banana sleeves from the 3 generations were validated in field by bagging bunches of bananas to qualitatively analyze possible disorders of postharvest. The validation was carried out in a banana plantation in the south of Gran Canaria island (the Canary Islands, Spain). Control banana sleeves of LDPE were used for comparison. The bags were located in bunches of bananas with approximately the same age and orientation for a proper comparison. Every 20-30 days, approximately, a visual evaluation was carried until the final harvest, which happened between 7 and 11 weeks later. Therefore, three visual inspections were made (installation, midterm and harvest days).

\subsection{Composting and Biodegradability Tests}

The analysis of composting (as a packaging product) was carried out considering the conformity to the standard EN 13432:2001, that includes the procedures of characterization, biodegradability, disintegration, compost quality and ecotoxicity. This analysis was carried out with the final compounding material (3rd generation).

\subsubsection{Initial Characterization}

The identification and characterization of the products was carried out according to EN 13432:2001 by heavy metal and fluorine analysis. Samples of up to $0.5 \mathrm{~g}$ were digested in $9 \mathrm{~mL}$ of concentrated nitric acid and $3 \mathrm{~mL}$ hydrochloric acid for $15 \mathrm{~min}$, using microwave heating with a Microwave Digestion Mod. Ethos Touch-Milestone (Milestone Srl, Bergamo, Italy). The sample and acid were placed in suitably inert polymeric microwave vessels, which were sealed and heated in the microwave system. The temperature profile was specified (reaching $180 \pm 5^{\circ} \mathrm{C}$ in approximately $5.5 \mathrm{~min}$ and remaining at $180 \pm 5^{\circ} \mathrm{C}$ for $9.5 \mathrm{~min}$ for the completion of specific reactions). After cooling, the vessel content was filtered, centrifuged, or allowed to settle and then decanted, diluted to volume, and analyzed by the appropriate ICP method (SW-846 methods) in an ICP-OES spectrometer, Mod. Optima 5300 DV, (PerkinElmer, Inc., Waltham, PA, USA) to obtain the concentrations of Cd, $\mathrm{Cr}, \mathrm{Cu}, \mathrm{Hg}, \mathrm{Ni}, \mathrm{Pb}$ and $\mathrm{Zn}$ according to UNE EN 13657:2004 and UNE EN 17294-2:2016.

The fluorine content was also quantified according to ISO 14582:2016 (calorimetric bomb for the dissolution of the organic matter of the sample) and ISO 10304-1:2009 (ionic chromatography method for the quantification of fluorine concentration). An oxidation of the sample by combustion and subsequent determination by ion chromatography was performed to use this method for solids. The halogens and sulfur contained in the compounds were transformed into fluorides, chlorides, bromides and sulphates, which were then analyzed by liquid chromatography in liquid phase using conductivity detectors. A small volume of sample (2-3 mL) was introduced into an Ionic Chromatography ICS 1000, Dionex (Dionex Corporation, Sunnyvale, California, USA). The anions of interest were separated and measured.

\subsubsection{Composting Test}

The biodegradability test was evaluated according to EN ISO 14855-1:2013. The test requirements for validation, both for the "blank sample" (soil and compost mix) and for the reference sample (cellulose), involve a degree of biodegradation of the reference material (cellulose) higher than $70 \%$ after 6 months, and a difference between the amounts of $\mathrm{CO}_{2}$ produced lower than $20 \%$ from the average value of all blank samples.

Three samples were sieved to less than $2 \mathrm{~mm}$ particle size and then the present plant materials, stones and other inert materials were removed. Equal amounts of these sieved samples were mixed to prepare a laboratory mixture (by weight) of the soil sample for the biodegradability test. The remaining part of the separated soils and the mixture were stored in sealed containers, individually, at $4 \pm 1{ }^{\circ} \mathrm{C}$ for a maximum of one month. The studied conditions were two different soils (called "Lugnano" and "Gardea"), with and without inoculum (composted manure Archa Reagen R50046001). The concentration level of soil-inoculum was 25:1. 
The reference material was microcrystalline cellulose, with two concentration levels of cellulose (C) (300 and $600 \mathrm{mg} \mathrm{C}$ ) and $50 \mu \mathrm{m}$ average particle size, produced by ALDRICH, distributed by SIGMA ALDRICH SRL.

A dry soil weight between 229.3 and $230 \mathrm{~g}$ was placed in each vessel with a dry compost weight between 7.7 and $8.3 \mathrm{~g}$ while the dry reference material weight used was in a range of 0.57 and $0.6 \mathrm{~g}$ with a theoretical average production of $\mathrm{CO}_{2}$ of $0.97 \mathrm{~g}$. The vessels of test material were prepared using a range of 0.94 and $0.96 \mathrm{~g}$ dry weight. In all cases, $32.3 \mathrm{~g}$ of water were added.

\subsubsection{Disintegration Test and Final Compost Quality}

Disintegration and the effects on the biological treatment process were carried out according to ISO 16929:2013 using an inoculum (soil and compost) as a substrate and operating at a controlled room temperature. The same inoculum (composted manure Archa Reagen R50046001) and the same soil-inoculum ratio (25:1) were used as in the biodegradability test. The main parameters of the inoculum and the test material (3rd generation) are shown in Table 7.

Table 7. Inoculum and test material characterization.

\begin{tabular}{ccccccc}
\hline Parameters & $\begin{array}{c}\text { Carbon } \\
\text { (\% D.M.) }\end{array}$ & $\begin{array}{c}\text { (\% } \\
\text { Nitrogen } \\
\text { (\% D.M.) }\end{array}$ & $\begin{array}{c}\text { Humidity } \\
\text { (\%) }\end{array}$ & $\begin{array}{c}\text { Volatile } \\
\text { Solids 550 } \\
\text { (\% D.M.) }\end{array}$ & pH & C/N Ratio \\
\hline Inoculum & 1.8 & 0.127 & 25.0 & 7.0 & 7.93 & 14.2 \\
Test material & 21.5 & $190-195$ & 1.05 & 99.46 & - & - \\
\hline
\end{tabular}

${ }^{1}$ Dry matter.

For the disintegration test and the assessment of the quality of the final compost, the test material was prepared by using the $3 \mathrm{rd}$ generation film reduced to $10 \times 10 \mathrm{~cm}$ pieces. The composting vessels were 4 for control (inoculum alone) and 2 for the test material (inoculum with $1 \mathrm{wt} \%$ of test material). In parallel, 4 additional composting vessels with the test material were also prepared to obtain the substrate used for the ecotoxicity test described in Section 2.7.4 (in this case, the test material was obtained from pellets of the final compounding, which were milled with nitrogen). Each vessel was filled with approximately the same amount of inoculum $(1 \mathrm{~kg})$. In the case of the test material vessels, the inoculum and test material were carefully mixed, maintaining the $1 \mathrm{wt} \%$ of test material content. Then, the containers were closed, and the test was started in the incubation chamber at a controlled temperature of $25 \pm 2{ }^{\circ} \mathrm{C}$.

The evaluation of the negative effects on the degradation process and the quality of the final compost were evaluated on the substrate provided by the disintegration test in order to meet the requirements of the National Real decree 506/2013 on fertilizers-Class A, and the European Regulation (EU) 2018/848 on organic production and labelling of organic products (the same values for each specific limit). For that, the concentrations of heavy metals were again evaluated, with the same procedures and equipment as in the initial characterization, but, in this case, also assessing the difference between the substrates with and without the test material, to consider the quality of the initial substrate. CrVI was evaluated according to EPA 3060A 2007 and EPA 7196A 1992. In summary, the following criteria were applied (where $\mathrm{L}$ is the reference regulatory limit):

- $\quad$ Case 1: Acceptance if the concentration values of both the substrate alone (A), and the substrate and test material (B), are equal or lower than $\mathrm{L}(\mathrm{A}$ and $\mathrm{B} \leq \mathrm{L})$.

- Case 2: When the previous condition is not fulfilled, acceptance if the difference between the concentrations of the substrate and test material (B), and the substrate alone $(\mathrm{A})$, are equal or lower than $\mathrm{L}(\mathrm{B}-\mathrm{A} \leq \mathrm{L})$. This additional criterion allows evaluating the real effect of the test material regardless of the quality of the initial substrate. 


\subsubsection{Ecotoxicity}

Assessing the toxicity of waste disintegrated by higher plants was performed according to OECD 208:2006 adopting the requirements reported in Annex E of the EN13432. Plant toxicity was evaluated using barley (Hordeum vulgare, from Bavicchi S.p.A.) and cress (Lepidium sativum, from ISI Sementi S.p.A.). The germination rates of these plants are $100 \%$ (barley) and $85 \%$ (cress).

As described in ISO 17556, standard soil was obtained from natural soil taken from cultivated fields. It was sieved with a $2 \mathrm{~mm}$ mesh to remove stones and other corpuscular material such as organic solids that could be fermented during the test. To inactivate any pathogenic microorganisms and seeds of wild plants, the standard soil was treated at $150{ }^{\circ} \mathrm{C}$ for $3 \mathrm{~h}$. The standard soil had a granulometry lower than $2 \mathrm{~mm}$, $\mathrm{pH}$ of 6.91 , water retention capacity of $31.5 \%$, organic carbon content of $1.4 \%$ and $2.4 \%$ of organic matter.

The test soil was obtained from the disintegration test described in Section 2.7.3, in which 4 vessels were used for ecotoxicity test by preparing $1 \mathrm{wt} \%$ test material milled with liquid nitrogen and $99 \%$ inoculum, thoroughly mixed and stabilized for 3 months at $25{ }^{\circ} \mathrm{C}$. At least once a week, the material was mixed to promote oxygenation and prevent surface dehydration and moisture accumulation on the bottom of the containers.

The control soil and test soil, previously air-dried for $24 \mathrm{~h}$, were added to standard soil at 25 and $50 \mathrm{wt} \%$ concentration. Every pot was sown with 100 seeds. Three replicas were set up for each series of tests. Pots were incubated in a growth chamber in these conditions:

- Lighting for $16 \mathrm{~h}$ a day at minimum of $3000 \mathrm{~lx}$ (with light at a wavelength suitable for photosynthesis), at $25^{\circ} \mathrm{C}$ and $70 \%$ relative humidity.

- Dark phase of $8 \mathrm{~h}$ a day, at $20^{\circ} \mathrm{C}$ and $80 \%$ of relative humidity.

- Incubation period: $14-21$ days from the time that $50 \%$ of the control plants are germinated.

The crops were monitored daily and maintained at the right level of humidity, being gently sprayed when necessary. At the end of the test, the plants were harvested and the number of plants per pot (germination) and the fresh weight of biomass (wet weight) per pot were evaluated.

According to point A4 of Annex A of EN 13432 standard, the germination rate and the plant biomass of both plant species, at each percentage tested, must be at least $90 \%$ of that of the control test.

For the test validity in control cultures, the following criteria must be respected:

- At least $70 \%$ of the seeds must germinate.

- At least $90 \%$ of these must survive throughout the test.

- Grown plants must show no phytotoxic effects (necrosis, chlorosis, rot, etc.).

\section{Results and Discussion}

\subsection{Preliminary Test}

This subsection explains the main results of the preliminary tests, which were used to optimize the three different generations of biofilms. Note that these preliminary tests started before the production of the 1st generation of biofilms, but continued until the 2nd generation.

\subsubsection{Compounding Extrusion Preliminary Results}

The preliminary test revealed that fiber of $3 \mathrm{~mm}$ length was better for compounding extrusion than fiber of $5 \mathrm{~mm}$. Moreover, no problems were found in the process for banana fiber percentages up to $5 \mathrm{wt} \%$. For higher percentages, the extruded thread was very stiff and broke frequently. This problem was solved by using slower conditions in the pelletization, but the processing speed was too low for an industrial environment (approximately $7 \mathrm{~kg} / \mathrm{h}$ ). Therefore, the optimal fiber content was set in $5 \mathrm{wt} \%$ for the different film generations. 
Small air bubbles were also observed in the compounds, probably due to fiber humidity. For this reason, the fiber was dried at $100-110^{\circ} \mathrm{C}$ for $12 \mathrm{~h}$ before compounding extrusion for the subsequent tests and the production of the three generations of biofilm.

\subsubsection{Preliminary Mechanical Test}

Approximately 5-7 specimens for each composition of PLA Ingeo 4032 D (Table 4) were tested under tensile tests, obtaining the results depicted in Figure 2.

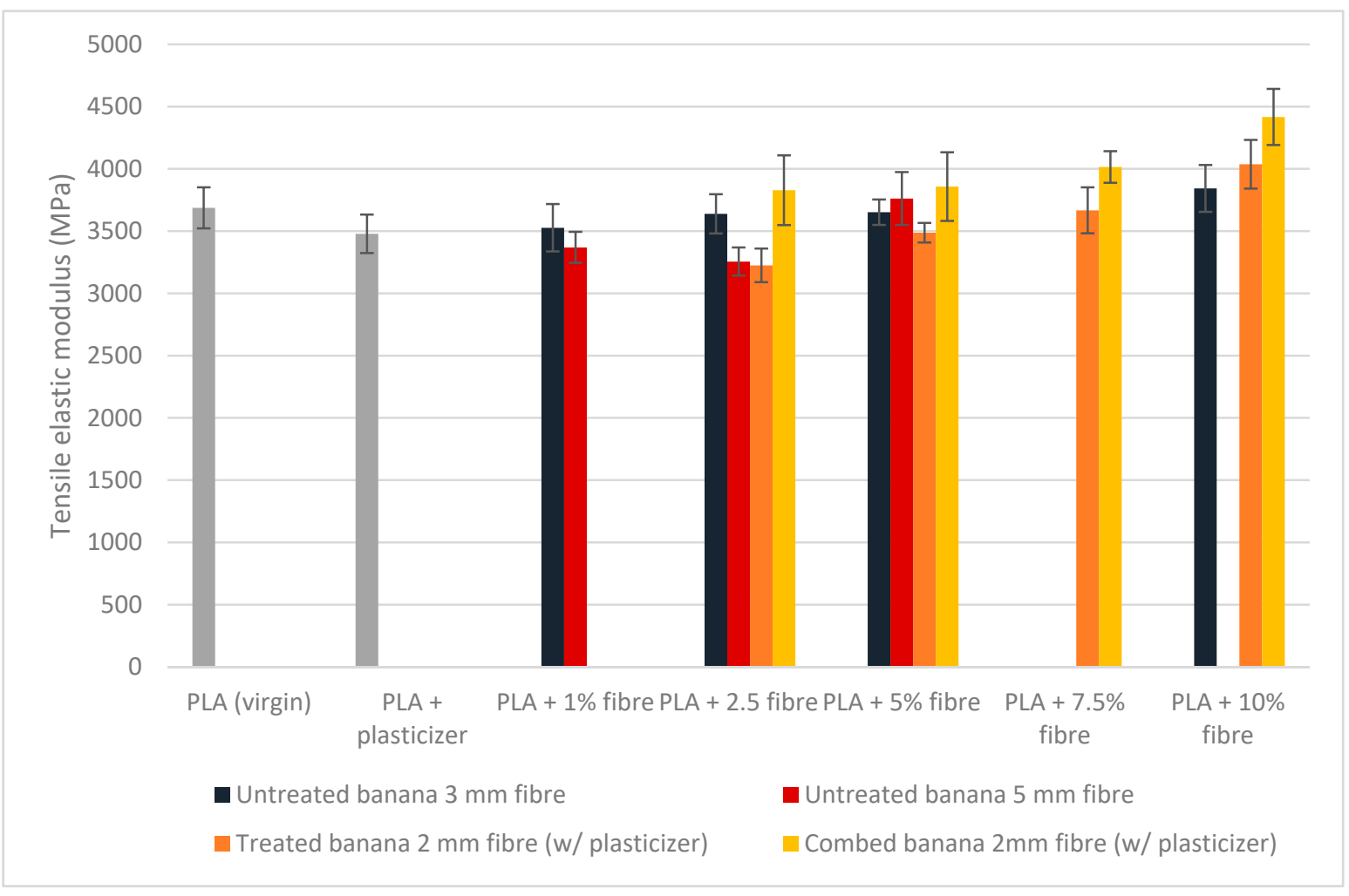

Figure 2. Tensile elastic modulus, PLA Ingeo 4032 D with different fiber percentages.

Treated and combed banana fiber compounds had $7 \mathrm{wt} \%$ plasticizer, while the others did not. The plasticizer content decreases the mechanical properties of the compounds, so they cannot be compared without taking this into account. Despite this, composites with untreated combed banana fibers had the highest tensile elastic modulus and the samples did not significantly degrade during the processing with PLA at $180-190{ }^{\circ} \mathrm{C}$. For this reason, the $\mathrm{NaOH}$ treatment was suppressed for the development of the 3rd generation of biofilm. This improved the sustainability of the process as the $\mathrm{NaOH}$ treatment requires more resources and an additional drying step, while the combing process was directly implemented in the fiber extraction machine by adding brushes at the end/output of the rotary scraping module [40].

A good fiber dispersion was visible to the naked eye on the fracture face of the samples. Since the difference between the polymer and fiber is very small both in density and composition, the fibers and polymer were difficult to distinguish on SEM images (electrons are backscattered in the same way by the carbon atoms). The interphase between the fiber and polymer can be appreciated in Figure 3. 


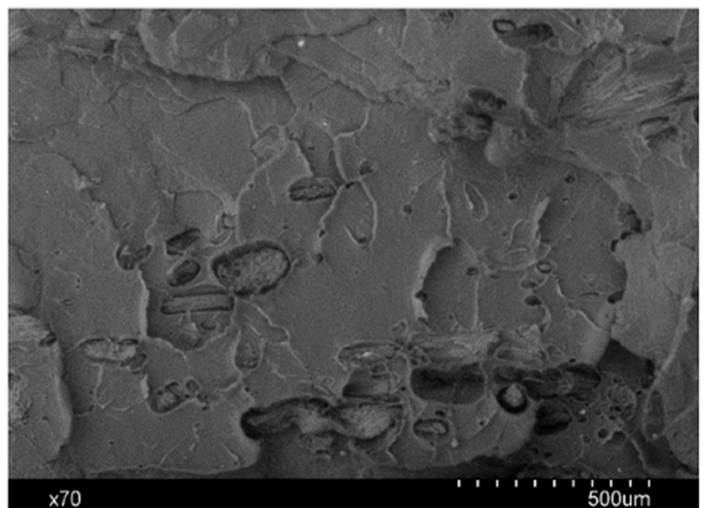

(a)

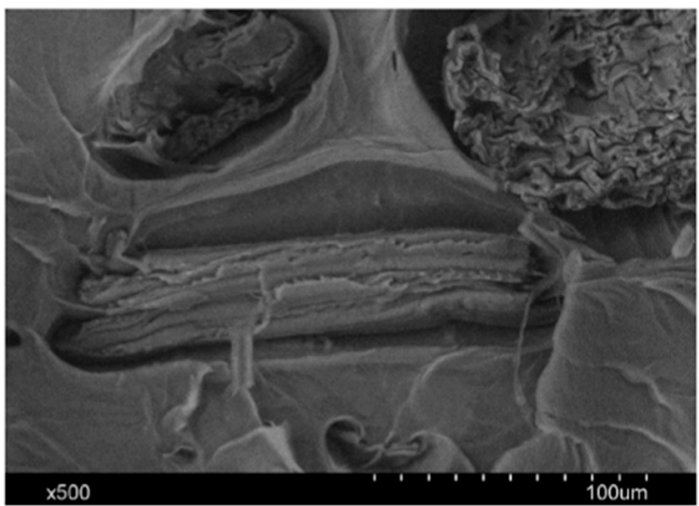

(b)

Figure 3. PLA and $5 \mathrm{~mm}$ fiber interphase, SEM micrography, $(\mathbf{a}) \times 70,(\mathbf{b}) \times 500$.

\subsubsection{Film Blowing Preliminary Test}

The preliminary test to optimize the process parameters (PLA and composite of PLA with banana fiber) started with virgin PLA. The bubble in the virgin PLA blowing was not very stable and had many wrinkles due to the high stiffness. To reduce these defects, the extruder temperature was increased and the tower was raised until its maximum height (bubble length of $2 \mathrm{~m}$ ). To compensate the greater bubble, more inlet air was introduced and the material flow was also increased up to $68 \mathrm{rpm}$. Due to high PLA stiffness, sometimes the bubble created small zig-zag shapes, which were increased over time. For this reason, the addition of plasticizer was considered for subsequent tests.

Once the process was stable with virgin PLA, the trials with fiber began. The wrinkle and zig-zag problems disappeared since this composition was not stiff. The fiber was well dispersed. The thickness of the film varied from 180 to $280 \mu \mathrm{m}$ due to the presence or not of fibers. So, the film-blowing process with PLA and fibers were stable.

Compounding material with fiber and plasticizer was also tested (PLA $+2.5 \% 3 \mathrm{~mm}$ fibers $+5 \%$ plasticizer, and PLA $+2.5 \% 5 \mathrm{~mm}$ fibers $+5 \%$ plasticizer), using almost the same film-blowing parameters. The results were similar to PLA without plasticizer, but the film looked a bit softer, as expected.

Table 8 summarizes all the tests and optimal process parameters for the film blowing with virgin PLA, and PLA with banana fiber.

Table 8. Optimal film blowing parameters of the preliminary tests.

\begin{tabular}{ccccc}
\hline Compounding & Virgin PLA & PLA + 5\% 3 mm BF & PLA + 2.5\% 5 mm BF & $\begin{array}{c}\text { 1 PLA + 2.5\% BF + 5\% } \\
\text { Plasticizer }\end{array}$ \\
\hline Extruder screw speed $(\mathrm{rpm})$ & 68 & 68 & 55 & 59 \\
Extruder temperature range $\left({ }^{\circ} \mathrm{C}\right)$ & $190-195$ & $190-195$ & $195-195$ & $190-195$ \\
Die temperature range $\left({ }^{\circ} \mathrm{C}\right)$ & $165-185$ & $100-185$ & $160-180$ & $160-185$ \\
Melt pressure (bar) & 295 & 295 & 386 & 295 \\
Cooling air speed (rpm) & 351 & 164 & 350 & 351 \\
Vertical nip roll speed (m/min) & 2.0 & 2.2 & 2.4 & 2.0 \\
Windup speed $(\mathrm{m} / \mathrm{min})$ & 3.0 & 4.4 & 3.3 & 3.0 \\
Bubble height $(\mathrm{m})$ & 2.0 & 1.9 & 1.8 & 1.7 \\
\hline
\end{tabular}

\footnotetext{
${ }^{1}$ Parameters for composites with $3 \mathrm{~mm}$ and $5 \mathrm{~mm}$ long fibers.
} 


\subsection{Development of Reinforced Biopolymers}

\subsubsection{Compounding Extrusion}

After the previously explained preliminary tests, the rest of the formulations were extruded. Table 9 shows the optimal parameters used for each biopolymers of the 1st generation.

Table 9. 1st film generation compounding extrusion parameters.

\begin{tabular}{|c|c|c|c|c|c|}
\hline Compounding ${ }^{1}$ & $\begin{array}{c}\text { Total Flow Rate } \\
(\mathrm{kg} / \mathrm{h})\end{array}$ & $\begin{array}{l}\text { Screw Speed } \\
\quad(\mathrm{rpm})\end{array}$ & $\begin{array}{c}\text { Temperature Range } \\
\left({ }^{\circ} \mathrm{C}\right)\end{array}$ & $\begin{array}{l}\text { Extruder Pressure } \\
\text { (bar) }\end{array}$ & $\begin{array}{c}\text { Pelletiser Speed } \\
(\mathrm{rpm})\end{array}$ \\
\hline PLA & 12 & 200 & 170-180 & 4 & 20 \\
\hline Danimer & 11 & 150 & $150-160$ & 4 & 20 \\
\hline Mater-Bi & 7 & 100 & $145-155$ & 2 & 20 \\
\hline BioPBS & 12 & 100 & $150-160$ & 4 & 20 \\
\hline
\end{tabular}

${ }^{1}$ Both control and reinforced banana fiber composites.

Compounding extrusion of the 2nd and 3rd fiber generation with each biopolymer was carried out. Table 10 shows the process parameters of both generations (the 3rd generation focused on Mater-Bi, using the same process parameters, and with the only difference of using combed fiber instead of treated fiber). Although the optimal fiber content was set in 5\% according to the preliminary tests, compounding with 10\% banana fiber (and 5\% $\mathrm{TiO}_{2}$ ) was produced to carry out some film blowing tests at higher percentages. Therefore, these compounding with $10 \%$ of banana fiber were later blended with virgin material in a $1: 1$ ratio to reduce the fiber content to $5 \%$ (and the $\mathrm{TiO}_{2}$ content to $2.5 \%$ ) for the final film blowing.

Table 10. The 2nd and 3rd film generation compounding extrusion parameters.

\begin{tabular}{|c|c|c|c|c|c|c|}
\hline Compounding & $\begin{array}{l}\text { Polymer Flow } \\
\text { Rate (kg/h) }\end{array}$ & $\begin{array}{l}\text { BF Flow Rate } \\
(\mathrm{kg} / \mathrm{h})\end{array}$ & $\begin{array}{l}\text { Screw Speed } \\
(\mathrm{rpm})\end{array}$ & $\begin{array}{c}\text { Extruder } \\
\text { Temperature } \\
\text { Range }\left({ }^{\circ} \mathrm{C}\right)\end{array}$ & $\begin{array}{c}\text { Extruder } \\
\text { Pressure (bar) }\end{array}$ & $\begin{array}{c}\text { Pelletiser } \\
\text { Speed (rpm) }\end{array}$ \\
\hline PLA (control) & 15 & - & 110 & $150-167$ & 4 & 20 \\
\hline $\mathrm{PLA}+10 \% \mathrm{BF}$ & 12 & 1.3 & 110 & $150-167$ & 4 & 20 \\
\hline${ }^{1}$ Mater-Bi (control) & 15 & - & 100 & $145-165$ & 2 & 20 \\
\hline${ }^{1}$ Mater-Bi $+10 \%$ BF & 12 & 1.3 & 110 & $145-165$ & 2 & 20 \\
\hline BioPBS (control) & 12 & - & 100 & 140-155 & 4 & 20 \\
\hline $\mathrm{BioPBS}+10 \% \mathrm{BF}$ & 12 & 1.3 & 100 & $140-150$ & 4 & 20 \\
\hline
\end{tabular}

${ }^{1}$ Both 2nd and 3rd generations.

Treated fibers showed less degradability after being extruded (lighter color of the resulting specimens) compared to untreated ones.

All the extruded formulations of the 2nd and 3rd generations were later micronized to improve the film blowing processability.

\subsubsection{Mechanical Test}

The tensile elastic modulus of each formulation (mold injected samples of the 1st generation compounds) was determined to compare among the different fiber types/percentages and polymeric matrices (Figure 4). 


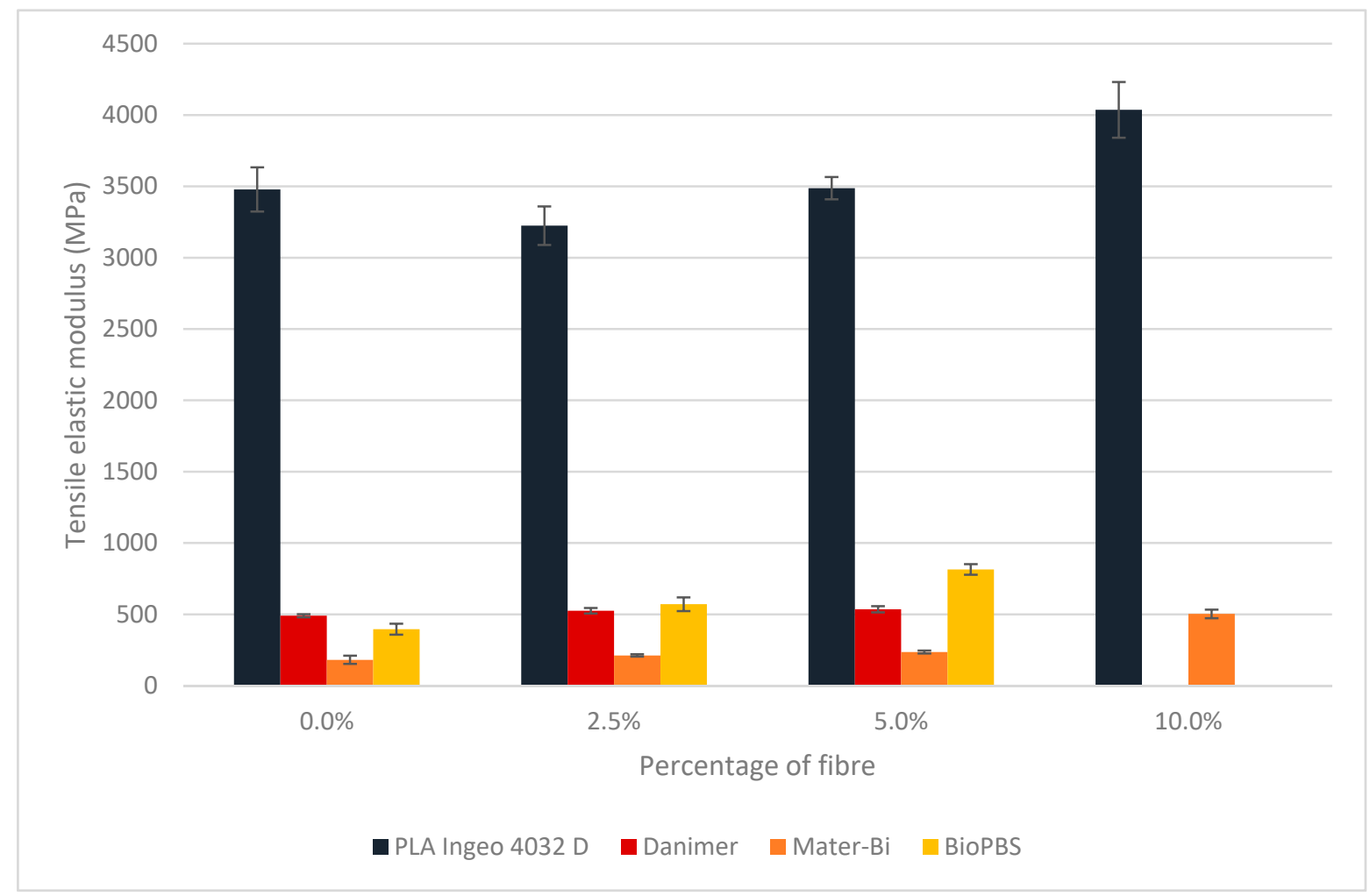

Figure 4. Comparison of tensile elastic modulus of the 1st generation compounds.

Commercial LDPE such as Riblene FF 33 F from Versalis has a tensile elastic modulus of $180 \mathrm{MPa}$, which is similar to other commercial LDPE. However, higher tensile elastic modulus (up to $520 \mathrm{MPa}$ ) have been found [45]. Therefore, conventional LDPE sleeves for banana bunches are within this range of elastic modulus (180-520 MPa). Table 11 shows the comparison of the developed composites with these limit values. For all the composites, the tensile elastic modulus was higher than the LDPE reference values, except for Mater-Bi, which was within the range.

Table 11. Tensile elastic modulus comparison of the 1st generation compounds with the reference values of LDPE (180 and $520 \mathrm{MPa})$.

\begin{tabular}{cccc}
\hline Sample & $\begin{array}{c}\text { Tensile Elastic } \\
\text { Modulus (MPa) }\end{array}$ & $\begin{array}{c}\text { Comparison to 180 MPa } \\
\mathbf{( \% )}\end{array}$ & $\begin{array}{c}\text { Comparison to 520 MPa } \\
(\%)\end{array}$ \\
\hline PLA + 5\% 2 mm BF & $3487.5 \pm 78.7$ & 1937.5 & 670.7 \\
Danimer + 5\% 2 mm BF & $535.5 \pm 22.1$ & 297.5 & 103.0 \\
Mater-Bi + 5\% 2 mm BF & $235.9 \pm 10.3$ & 131.1 & 45.4 \\
BioPBS + 5\% 2 mm BF & $814.9 \pm 37.4$ & 452.7 & 156.7 \\
\hline
\end{tabular}

Table 12 compares the tensile elastic modulus of the reinforced composites (1st generation fiber) with the control samples (no fiber content). The elastic modulus increased with the fiber content for all the cases, but it was more significant for polymers with low elastic modulus such as Mater-Bi (+30.1\%) and BioPBS (+105.7\%). 
Table 12. Tensile elastic modulus comparison of the 1st generation with the control sample (without fiber).

\begin{tabular}{cccc}
\hline Sample & $\begin{array}{c}\text { Tensile Elastic } \\
\text { Modulus (MPa) }\end{array}$ & $\begin{array}{c}\text { Tensile Elastic Modulus } \\
\text { (Control Sample) (MPa) }\end{array}$ & $\begin{array}{c}\text { Value Compared to } \\
\text { Control (\%) }\end{array}$ \\
\hline PLA + 5\% 2 mm BF & $3487.5 \pm 78.7$ & $3478.2 \pm 154.9$ & 100.3 \\
Danimer + 5\% 2 mm BF & $535.5 \pm 22.1$ & $490.1 \pm 10.5$ & 109.3 \\
Mater-Bi + 5\% 2 mm BF & $235.9 \pm 10.3$ & $181.3 \pm 29.2$ & 130.1 \\
BioPBS + 5\% 2 mm BF & $814.9 \pm 37.4$ & $396.1 \pm 38.8$ & 205.7 \\
\hline
\end{tabular}

Regarding the 2nd generation (treated banana fiber, in this case also sieved, and $\mathrm{TiO}_{2}$ content of $2.5 \%$, instead of $3 \%$ as in the 1 st generation), Figure 5 shows the corresponding tensile elastic modulus for each compounding. Again, the elastic modulus increased with the fiber content for all the biopolymers.

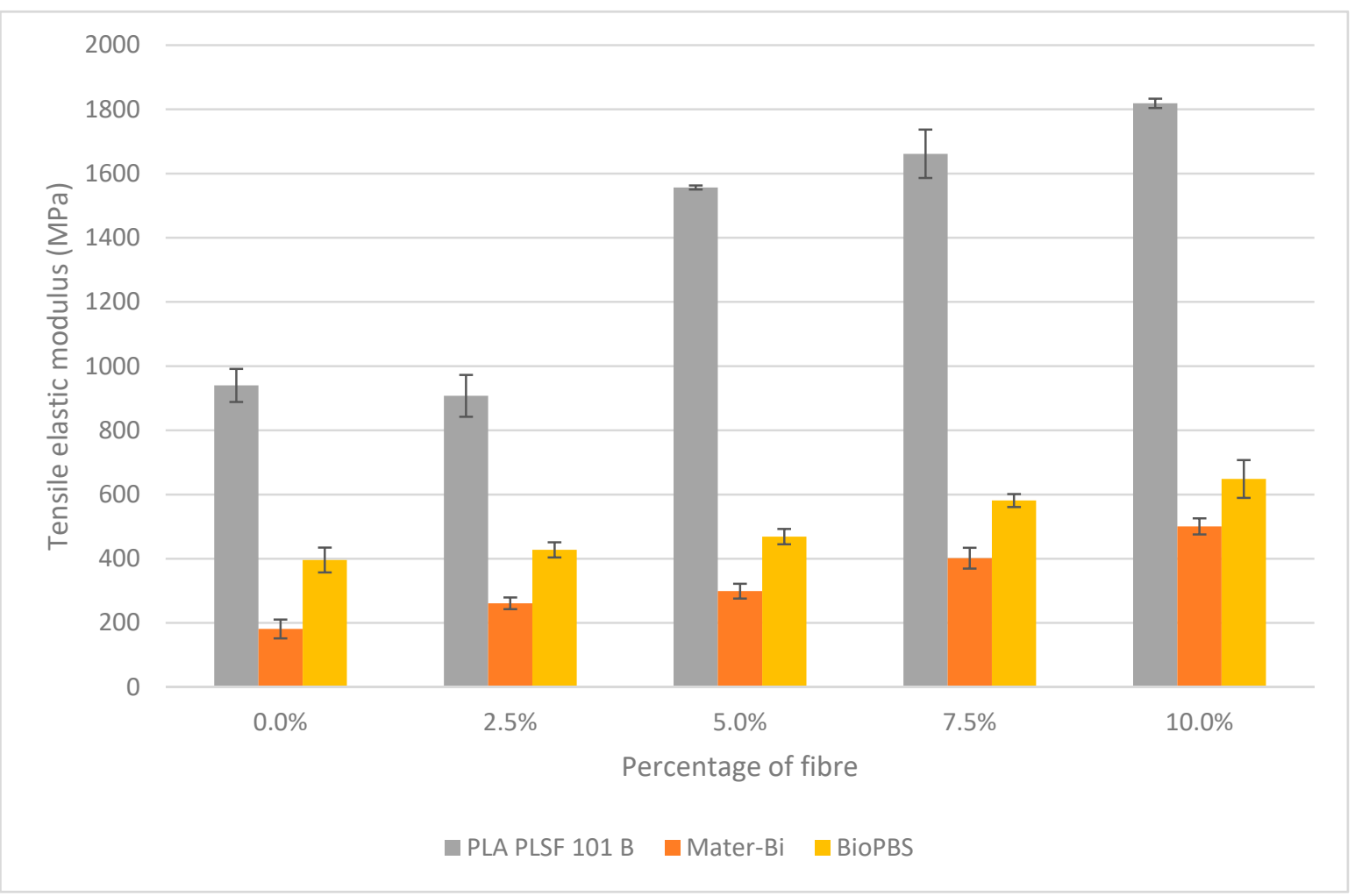

Figure 5. Comparison of the tensile elastic modulus of the 2nd generation compounds.

Table 13 compares the tensile elastic modulus of the 2nd generation compounds ( $5 \%$ fiber) with the control sample (without banana fiber). The 2nd fiber generation increased to a larger extent the elastic modulus of the PLA PLSF $101 \mathrm{~B}(+65.6 \%)$ compared to the 1st generation PLA $(+0.3 \%)$. This is due to the higher reinforcing effect of the fiber in matrices with lower mechanical properties, as it happens with PLA PLSF 101 B (more flexible than PLA Ingeo Biopolymer 4032 D).

Table 13. Tensile elastic modulus comparison of the 2nd generation with the control sample (without fiber).

\begin{tabular}{cccc}
\hline Sample & $\begin{array}{c}\text { Tensile Elastic } \\
\text { Modulus (MPa) }\end{array}$ & $\begin{array}{c}\text { Tensile Elastic Modulus } \\
\text { (Control Sample) (MPa) }\end{array}$ & $\begin{array}{c}\text { Value Compared to } \\
\text { Control (\%) }\end{array}$ \\
\hline PLA + 5\% 2 mm BF & $1556.4 \pm 6.4$ & $940.0 \pm 51.6$ & 165.6 \\
Mater-Bi + 5\% 2 mm BF & $299.1 \pm 23.1$ & $181.3 \pm 29.2$ & 165.0 \\
BioPBS + 5\% 2 mm BF & $468.6 \pm 23.9$ & $396.1 \pm 38.8$ & 118.3 \\
\hline
\end{tabular}


Table 14 shows a comparison between the 2 nd and 1 st compound generations with $5 \%$ fiber content.

Table 14. Comparison of the tensile elastic modulus between the 2nd and 1st generations.

\begin{tabular}{ccc}
\hline Sample (2nd Generation) & $\begin{array}{c}\text { Tensile Elastic Modulus } \\
\text { (MPa) }\end{array}$ & $\begin{array}{c}\text { Value Compared to 1st Gen } \\
\text { (\%) }\end{array}$ \\
\hline PLA + 5\% 2 mm BF & $1556.4 \pm 6.4$ & $44.6 *$ \\
Mater-Bi + 5\% 2 mm BF & $299.1 \pm 23.1$ & 126.8 \\
BioPBS + 5\% 2 mm BF & $468.6 \pm 23.9$ & 57.5 \\
\hline
\end{tabular}

* The PLA used in the 2nd generation was different (PLA PLSF 101 B, more flexible).

In the comparison between PLA samples, it must be noted that the PLA was different between the 1 st and 2 nd generations. For Mater-Bi, a $26.8 \%$ increase was achieved in the 2nd generation. In the case of BioPBS, a clear decrease $(-42.5 \%)$ was observed.

Since the micronizing was going to be applied in the 2 nd compounding generation to improve the film-blowing process, specimens of micronized compounds were also mold injected and subjected to tensile tests to compare the results of micronized and nonmicronized samples. This test was carried out with PLA PLSF $101 \mathrm{~B}$ and 5\% 2nd generation fiber. The tensile elastic modulus of the micronized material was $1675.56 \mathrm{MPa}, 8 \%$ higher than the non-micronized blend $(1556.39 \mathrm{MPa})$. This proved that, since the fiber is cut in both directions and the length-thickness rate is maintained, the fiber reinforcement effect was similar both in the micronized and non-micronized materials. The broken specimens of the micronized PLA with the 2nd generation fiber blend were also observed by SEM on the fracture face. The interphase between the fiber and polymer, after micronization, mold injection and tensile test, can be appreciated in Figure 6.

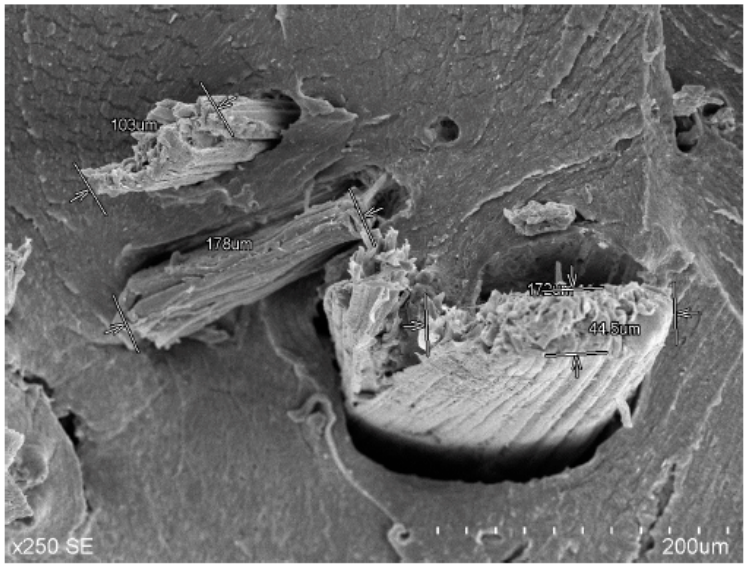

(a)

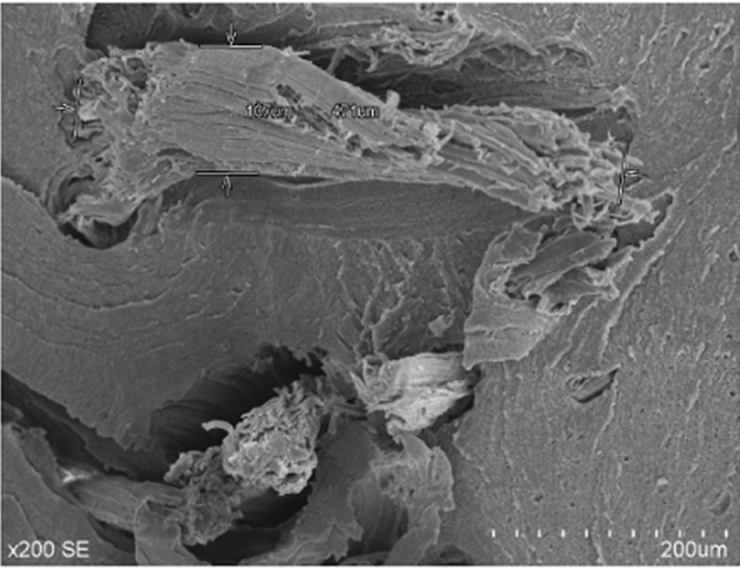

(b)

Figure 6. Micronized PLA with 5\% 2nd generation fiber interphase, SEM micrography, (a) $\times 250,(\mathbf{b}) \times 200$.

Since the preliminary tests showed that the combed fiber increased the mechanical performance of the composites and the degradation suffered during the compounding and film blowing processability was acceptable, the $\mathrm{NaOH}$ treatment was discarded for the 3rd film generation. Therefore, the 3rd generation of biofilms was produced with combed fiber without treatment, thus reducing the environmental impact and simplifying the process.

As a conclusion of the mechanical tests, the different compounds developed had higher mechanical properties compared to the LDPE reference values (180-520 MPa), except Mater-Bi compounds, which were always in this range. For the specific application of protective bags, high elastic modulus is not needed. In fact, according to the validation tests in field (Section 3.2.4), the stiffest bags (1st generation PLA compounding) were the worst ones (broken by the wind due to the high rigidity). Moreover, flexible bags are 
easier to handle. For this reason, the 3rd generation of biofilms was made exclusively with Mater-Bi biopolymer matrix, which had the best performance in the validation in field.

\subsubsection{Film Blowing}

Apart from the film-blowing preliminary tests carried out with PLA, another test was done with PLA and 10\% untreated fiber of the 1st generation. However, many holes appeared during the blowing. The compound was then diluted with control PLA down to $5 \%$, concluding again that the maximum feasible percentage for blowing was $5 \mathrm{wt} \%$. This test was also performed with the other biopolymers and the conclusions were similar: the maximum banana fiber content of $2 \mathrm{~mm}$ length that can be blown is approximately $5 \mathrm{wt} \%$, although some holes remained in some samples.

Table 15 shows the optimal film blowing process parameters used for the 1st generation of biofilms.

Table 15. 1st film generation optimal blowing parameters.

\begin{tabular}{ccccc}
\hline Compounding & PLA & Danimer & Mater-Bi & BioPBS \\
\hline Extruder screw speed $(\mathrm{rpm})$ & 75 & 45 & 71 & 62 \\
Extruder temperature range $\left({ }^{\circ} \mathrm{C}\right)$ & $185-195$ & $145-160$ & $145-160$ & $145-150$ \\
Die temperature range $\left({ }^{\circ} \mathrm{C}\right)$ & $171-185$ & $145-145$ & $140-161$ & $135-150$ \\
Melt pressure $(\mathrm{bar})$ & 312 & 333 & 425 & 274 \\
Cooling air speed $(\mathrm{rpm})$ & 300 & 1500 & 2500 & 1780 \\
Vertical nip roll speed (m/min) & 2.0 & 1.5 & 1.2 & 0.9 \\
Windup speed $(\mathrm{m} / \mathrm{min})$ & 3.9 & 2.5 & 2.6 & 1.9 \\
Bubble height $(\mathrm{m})$ & 1.8 & 1.7 & 1.7 & 1.7 \\
\hline
\end{tabular}

A first test with Mater-Bi and 7.5\% fiber content was performed, but big holes appeared and it was impossible to blow. The same test was carried out with $5 \%$ fiber content and some holes also appeared, but the air loss could be compensated by introducing more air (dedicated staff was needed for this task). Additionally, a low blowing speed was needed, as it gave time for the polymer to cool down.

In the case of BioPBS composites, and after adjusting the parameters with virgin BioPBS, film with 5\% banana fiber was blown. More material flow was needed in comparison with baseline formulation (without fiber), due to hole formation in the interface between fiber and polymer.

In the case of PLA bags, the wind broke them in the validation in field (Section 3.2.4) due to the high stiffness. That is why a different PLA from Natureplast (European manufacturer) was selected for the 2nd film generation (contact approved and more flexible). Since Danimer 21906 is not European and its performance in field was similar to the other biopolymers, it was also discarded for the 2nd biofilm generation. As for Mater-Bi EF04P and BioPBS, their performance was good, so they were maintained for the 2nd generation.

Since the developed films had holes and were too thick to meet the requirements of banana sleeves, a new approach was studied for the 2nd film generation to reduce the fiber length. The direct milling of the fiber was discarded due to the high complexity of the process. However, the micronization of the compounds was considered a feasible option to reduce the fiber length and consequently improve the film blowing extrusion and $\mathrm{bag} /$ fruit contact (to reduce the scratches observed in the validation in field, showed in Section 3.2.4). Therefore, for the 2nd biofilm generation, the compounding extrusion with $5 \%$ fiber content and $2.5 \% \mathrm{TiO}_{2}$ was carried out for all 3 biopolymeric matrices (BioPBS, PLA and Mater-Bi). The compounding materials were then micronized and blown. The processing blown film temperatures in the extruder for Mater-Bi were around $12{ }^{\circ} \mathrm{C}$ lower compared to the non-micronized material, whereas they remained the same in the die. The film-blowing process was more stable than the one with non-micronized material and the material flow could be decreased to reduce the thickness. No holes appeared but areas with different thickness were found. In the case of BioPBS (with 5\% 2nd generation fiber and 
$2.5 \% \mathrm{TiO}_{2}$ ), the processing temperatures of the micronized compounding in the extruder were around $20^{\circ} \mathrm{C}$ lower compared to the non-micronized material, and remained the same in the die. The film-blowing process was also more stable. In the case of PLA, although the blowing was improved compared to the previous generation, it was not as stable as with Mater-Bi or BioPBS. Holes kept appearing and the bubble diameter could not widen up. Although the new PLA was less stiff than the one used in the 1st film generation, it was still too stiff for a stable film-blowing process even with micronized fiber.

Since Mater-Bi bags performed better in the validation in field for the 2nd film generation, it was selected as the best biopolymer. Moreover, as the micronizing step significantly improved the performance and the film-blowing processability, it was also maintained. Therefore, Mater-Bi composites ( $5 \%$ fiber percentage and $2.5 \% \mathrm{TiO}_{2}$ ) were micronized and blown again for the 3rd film generation (Figure 7). The only difference was the fiber processing (the $\mathrm{NaOH}$ treatment was replaced by a combing step implemented in the fiber extraction machine). The processing temperatures in the extruder were set as in the 2nd generation. The film-blowing process was stable and the material flow could be decreased. No holes appeared and a thinner film was obtained.

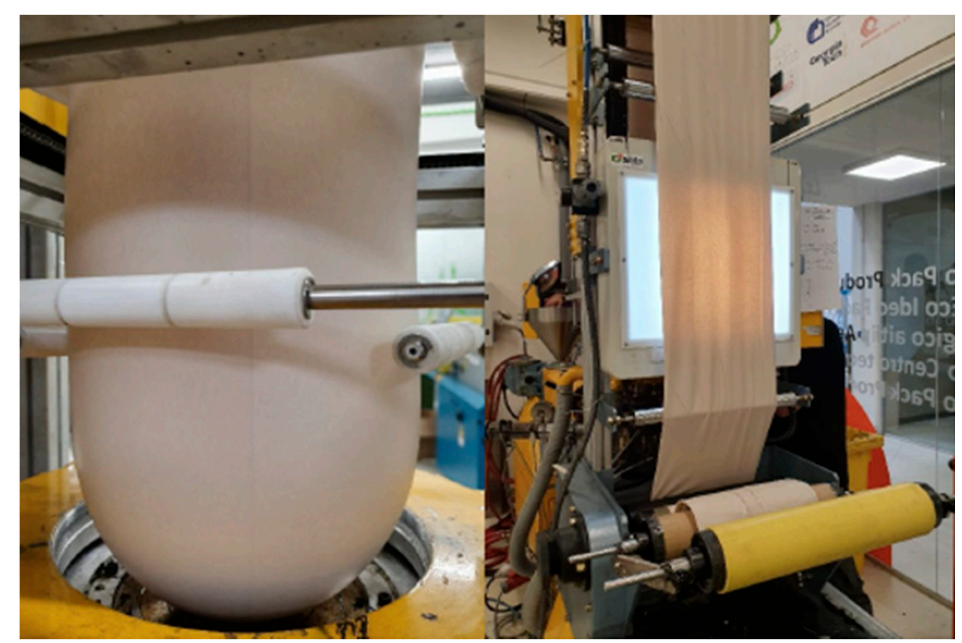

Figure 7. Blown film extrusion of micronized Mater-Bi EF04P with $2.5 \% \mathrm{TiO}_{2}$ and $5 \%$ 2nd generation fiber.

The optimal film-blowing process parameters for the 2nd and 3rd film generations are depicted in Table 16.

Table 16. The 2nd and 3rd film generation optimal blowing parameters.

\begin{tabular}{cccc}
\hline Compounding & PLA & Mater-Bi $\mathbf{~}^{\mathbf{1}}$ & BioPBS \\
\hline Extruder screw speed $(\mathrm{rpm})$ & 35 & 37 & 57 \\
Extruder temperature range $\left({ }^{\circ} \mathrm{C}\right)$ & $152-165$ & $138-148$ & $119-129$ \\
Die temperature range $\left({ }^{\circ} \mathrm{C}\right)$ & $158-168$ & $145-155$ & $116-127$ \\
Melt pressure $(\mathrm{bar})$ & 99 & 185 & 203 \\
Cooling airspeed $(\mathrm{rpm})$ & 1577 & 1503 & 1847 \\
Vertical nip roll speed $(\mathrm{m} / \mathrm{min})$ & 1.1 & 0.8 & 0.9 \\
Windup speed $(\mathrm{m} / \mathrm{min})$ & 2.1 & 1.5 & 1.8 \\
Bubble height $(\mathrm{m})$ & 1.4 & 1.5 & 1.5
\end{tabular}

${ }_{1}$ Parameters for both the 2nd and 3rd generations of Mater-Bi composites.

\subsubsection{Validation in Field}

For the 1st generation (Figure 8), the PLA banana sleeves tore down with the wind due to their rigidity. Therefore, this material was discarded for the subsequent generations. The other banana sleeves performed well. 


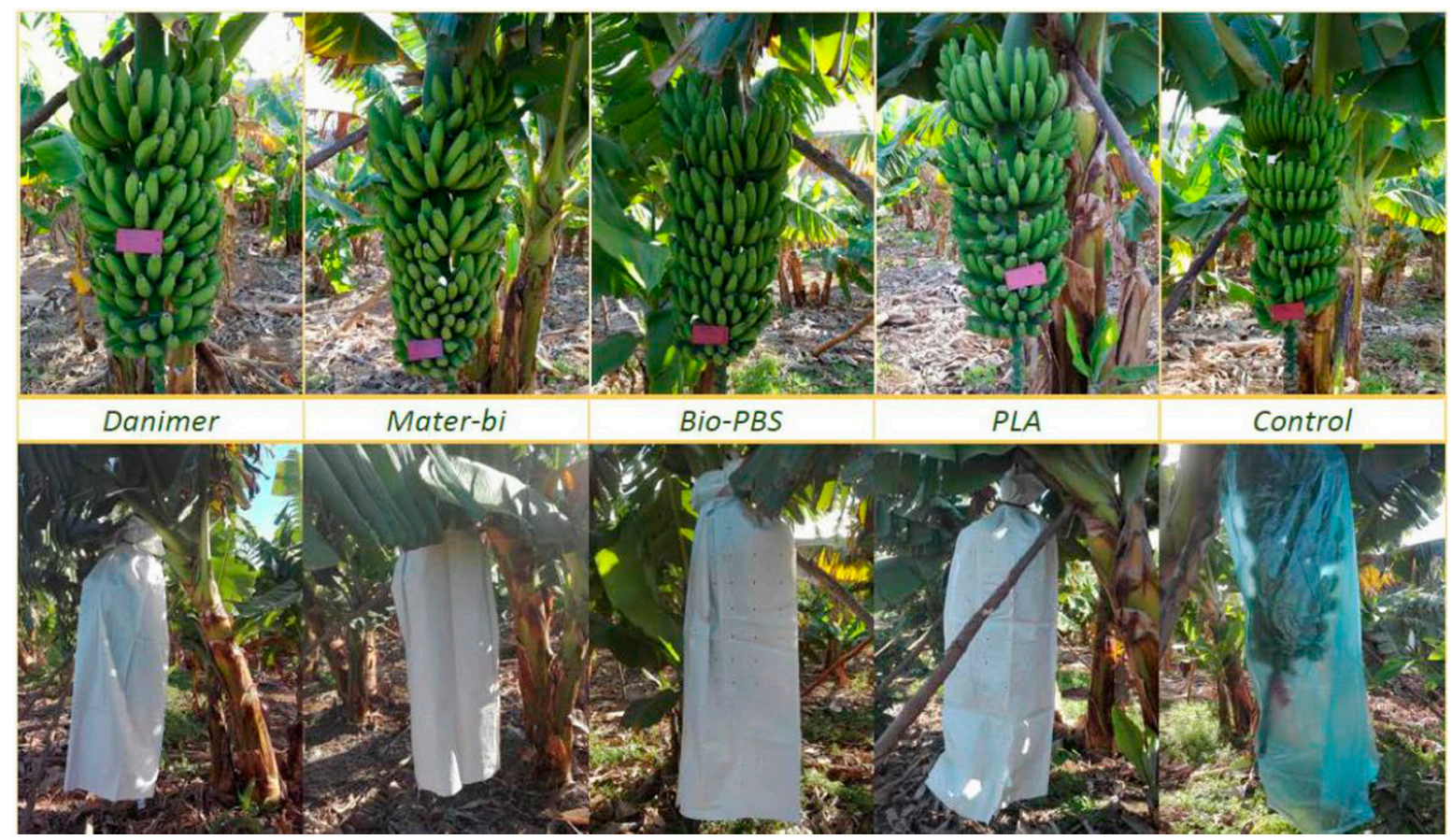

Figure 8. Banana sleeves tests on the plantation (1st generation).

According to the farmers' feedback, the bananas covered in all the sleeves grew correctly and the maturation was faster in the bananas covered with the developed sleeves compared to the control samples. This was due to the higher thickness of the novel sleeves, which was needed for the film-blowing processability. Moreover, some small scratches were found on the bananas of the developed bags, probably due to the roughness of the fiber. However, this did not have any important consequence in the final quality of the bananas, which were valid. In any case, as bananas are classified in different categories depending on the quality (dimensions, visual imperfections, etc.), farmers try to avoid these aesthetic defects (the better the category, the higher the market price).

For the 2nd generation of banana sleeves, a significant improvement in plastic/fruit contact was achieved. The micronizing step allowed the production of smoother bags (lower friction) and, consequently, no scratches were found in the bananas. This is an important achievement since any friction with the bananas, usually caused by the wind, may impact on the final appearance of the fruit. Among the bags produced in this 2nd generation, the PLA-based were discarded due to its high stiffness, while BioPBS was more expensive and performed worse than Mater-Bi bags. For this reason, Mater-Bi was selected as the best biomaterial.

In the 3rd biofilm generation (Mater-Bi with 5\% banana fiber), an improvement in the banana sleeves appearance was observed. The maturation of the banana bunches protected with the 3rd generation bags was between 1 and 2 weeks shorter compared to the control ones. Moreover, the developed bags were easier to put them on due to their higher consistency. This is a clear advantage for banana farmers, especially in colder periods in which the bunch of bananas is not always clearly separated from the plant and the process to put the sleeves on is more complex (sometimes, there is no space between the bananas and the plants, or between the bananas and the sticks used to fix the plant, thus hindering this process). In windy weather conditions, this higher stiffness or consistency is also an advantage to put them on (the wind folds the conventional bags very easily, thus hindering the process, while this does not happen with the developed bags). Despite this higher stiffness, the final 3rd generation bags demonstrated to be smooth enough to avoid scratches on the bananas and flexible enough to be easily knotted (farmers directly tie the bags to the stem of the bunch, on the top side). The only detail that should be improved 
for future developments or industrial application was the transparency of the biofilms. Protective banana bags are usually quite transparent to promote the greenhouse effect and, particularly, to enable the visual check by farmers (important feature for the harvest at the appropriate time and pest control). In the developed bags, this visual check had to be done by lifting the bag, which is more time-consuming compared to the remote visual check.

Figure 9 shows the validation in field of the 3rd bags generation.

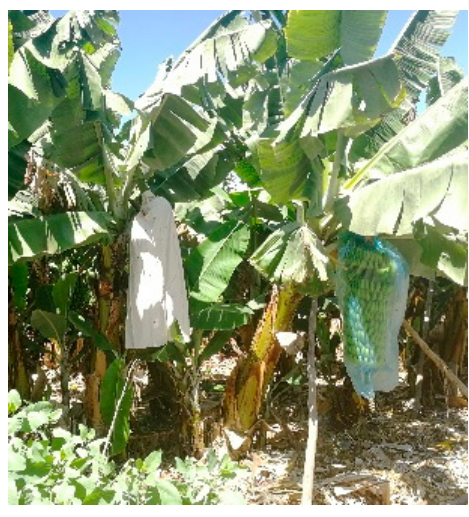

(a)

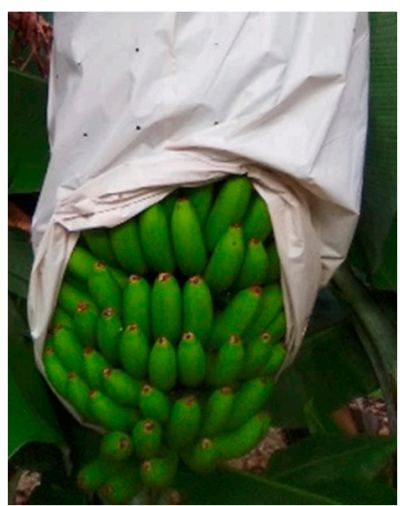

(b)

Figure 9. Validation in field of the 3rd biofilm generation, (a) control and developed bags after installation in field, (b) state of bananas during the maturation in the final developed bag.

\subsection{Biodegradability Test}

This section details the results of the biodegradability tests carried out with the 3rd generation biofilm (Mater-Bi with $5 \%$ banana fiber and $2.5 \% \mathrm{TiO}_{2}$ ).

\subsubsection{Initial Characterization}

The compounding of the 3rd generation of biofilms was identified and evaluated (Table 17). The detection limit for each element is also displayed.

Table 17. Heavy metals and fluorine analysis results.

\begin{tabular}{cccc}
\hline mg/kg (D.M.) & D.L. $^{\mathbf{1}}$ & Mater-Bi $+\mathbf{5} \% \mathbf{B F + 2 . 5 \%} \mathbf{~ T i O}_{\mathbf{2}}$ & Limit (EN 13432) \\
\hline Arsenic & 2.5 & $<$ D.L. & 5 \\
Cadmium & 0.19 & <.L. & 0.5 \\
Chromium & 0.5 & 0.75 & 50 \\
Copper & 1 & 1.52 & 70 \\
Lead & 2 & <D.L. & 50 \\
Mercury & 0.3 & <D.L. & 0.5 \\
Molybdenum & 0.5 & <D.L. & 1 \\
Nickel & 1 & <D.L. & 25 \\
Selenium & 0.5 & <D.L. & 0.75 \\
Zinc & 5 & 5.53 & 150 \\
Fluorine & 0.05 & <D.L. & 100 \\
\hline
\end{tabular}

${ }^{1}$ Detection limit for each element.

As expected, the heavy metal content in the developed compound was minimal.

\subsubsection{Composting Test}

The protective bags of the 3rd generation (maximum thickness of $25 \pm 10 \mu \mathrm{m}$ and dimensions of $1700 \times 810 \mathrm{~mm}$, with macro perforations) were subjected to biodegradability tests. The results are shown in Table 18. 
Table 18. Main biodegradability test results.

\begin{tabular}{|c|c|c|c|c|c|}
\hline Material & $\begin{array}{c}\text { Biodegradability } \\
(\%)\end{array}$ & Time (d) & $\begin{array}{l}\text { Total } \mathrm{CO}_{2} \\
\text { Production } \\
(\mathrm{mg})\end{array}$ & Final pH & $\begin{array}{c}\text { Average } \\
\text { Biodegradability } \\
(\%)\end{array}$ \\
\hline Blank 1 & - & - & 1001.0 & 7.91 & - \\
\hline Blank 2 & - & - & 878.5 & 7.88 & - \\
\hline Blank 3 & - & - & 929.8 & 7.98 & - \\
\hline R.M. ${ }^{1} 1$ & 100.5 & 180 & - & 7.89 & \\
\hline R.M. 2 & 98.6 & 180 & - & 7.82 & $99.3 \pm 13.8$ \\
\hline R.M. 3 & 98.7 & 180 & - & 7.88 & \\
\hline Test material 1 & 99.8 & 180 & - & 7.99 & \\
\hline Test material 2 & 99.3 & 180 & - & 8.01 & $99.3 \pm 0.5$ \\
\hline Test material 3 & 98.8 & 180 & - & 7.91 & \\
\hline
\end{tabular}

${ }^{1}$ Reference material.

The biodegradability test of the blanks showed values of $\mathrm{CO}_{2}$ production between 878.5 and $1001.0 \mathrm{mg}$, and a final $\mathrm{pH}$ between 7.88 and 7.98. The reference samples had an average biodegradability of $99.3 \pm 13.8 \%$ after 180 days and a similar $\mathrm{pH}$ average.

The test material complies with the requirements of EN 13432 for the biodegradability degree in soil conditions, providing an average biodegradation degree of $99.3 \pm 0.5 \%$ after 180 days (at the plateau value) and an average $\mathrm{pH}$ of 7.94. The results confirm the validation of the test since the quantity of carbon dioxide released from the blanks were within $20 \%$ of the average value at the end of the test, and the biodegradability of the reference material was higher than $70 \%$.

\subsubsection{Disintegration Test and Final Compost Quality}

As for the requirements of the European legislation for the main characteristics of mixed fertiliser and soil, the results are presented in Table 19. For the main parameters, the compliance with the limits was verified.

Table 19. Analysis of mixed fertiliser.

\begin{tabular}{|c|c|c|c|}
\hline Parameter & Soil (Control Sample) & $\begin{array}{c}\text { Mater-Bi }+5 \% \mathrm{BF} \\
+2.5 \% \mathrm{TiO}_{2}\end{array}$ & $\begin{array}{l}\text { Mixed } \\
\text { Fertiliser }\end{array}$ \\
\hline Plastics, glass, metals (>2 mm) (\%) & absent & 0.12 & $<0.5 \%$ D.M. \\
\hline Inert material $(>5 \mathrm{~mm})(\%)$ & absent & absent & $<5 \%$ D.M. \\
\hline Moisture $(\%)$ & 55.0 & 52.2 & $50-55 \%$ \\
\hline $\mathrm{pH}$ & 7.9 & 8.0 & 6-8.5 \\
\hline Organic carbon $(\%)$ & 22.9 & 20.0 & $\geq 20 \%$ D.M. \\
\hline Carbon/Nitrogen ratio (\%) & 14.5 & 11.8 & $<25 \%$ \\
\hline
\end{tabular}

Table 20 shows the results of the heavy metals analysis. The final composted residue for the test material complies with "Case 1" (Cadmium, Chromium VI, Copper, Mercury, Lead and Zinc) or "Case 2" (Chromium and Nickel). Consequently, the final substrate obtained from the test material can be accepted according to the National Real decree 506/2013 on fertilizers-Class A, and the European Regulation (EU) 2018/848.

Table 20. Heavy metals analysis results.

\begin{tabular}{|c|c|c|c|}
\hline mg/kg (D.M.) & Soil (Control Sample) & Mater- $\mathrm{Bi}+5 \% \mathrm{BF}+2.5 \% \mathrm{TiO}_{2}$ & Limit (EU 2018/848) \\
\hline Cadmium $^{1}$ & 0.26 & 0.23 & 0.7 \\
\hline Chromium VI ${ }^{1}$ & 0 & 0 & n.d. ${ }^{3}$ \\
\hline Copper $^{1}$ & 31.2 & 27.4 & 70 \\
\hline Mercury $^{1}$ & 0.11 & $<0.1$ & 0.4 \\
\hline Lead $^{1}$ & 18.7 & 17.8 & 45 \\
\hline Zinc $^{1}$ & 93 & 77 & 200 \\
\hline Total chromium ${ }^{2}$ & 262 & 178 & 70 \\
\hline Nickel $^{2}$ & 241 & 165 & 25 \\
\hline
\end{tabular}

${ }^{1}$ Compliance with Case $1 .{ }^{2}$ Compliance with Case $2 .{ }^{3}$ Not detected. 


\subsubsection{Ecotoxicity Test}

The ecotoxicity tests were stopped after 22 days ( 16 days after the germination of $50 \%$ of the control plants). No visual injury was detected in any plants of all cultures set up for these tests (Figure 10). Table 21 shows the average and standard deviation values of germinated plants and fresh biomass of the plants with the test soil. The germination rate (germination with the test soil compared to the control soil) and fresh biomass weight rate (wet weight of the biomass with the test soil compared to the control soil) were also calculated.

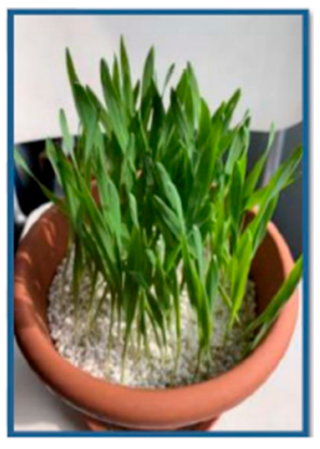

(a)

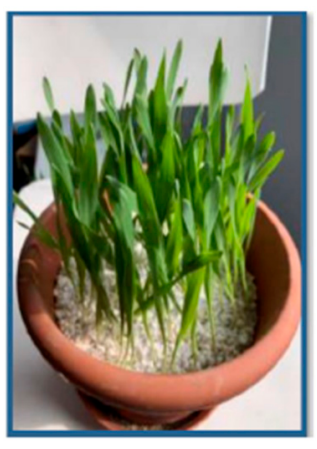

(b)

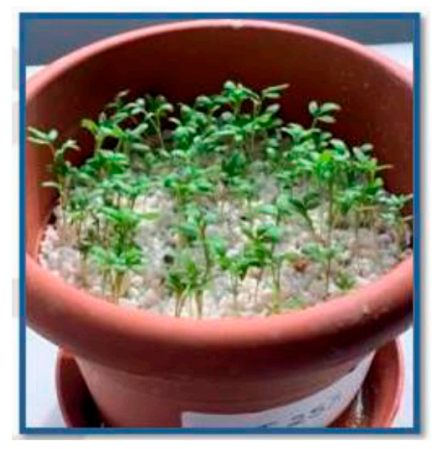

(c)

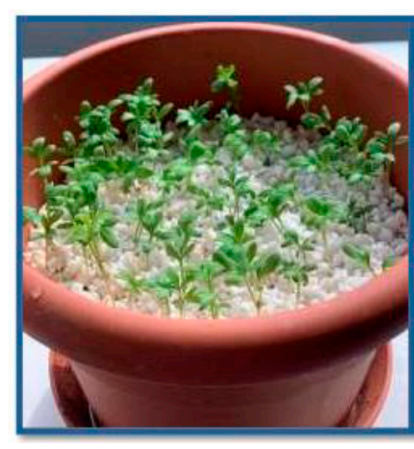

(d)

Figure 10. Visual presentation of plants, (a) barley control, (b) barley sample, (c) cress control, (d) cress sample.

Table 21. Values of germinated plants and fresh biomass with the test soil.

\begin{tabular}{ccccccccc}
\hline \multirow{2}{*}{ Plant } & \multirow{2}{*}{$\begin{array}{c}\text { Test Soil } \\
\text { Concentration (\%) }\end{array}$} & \multicolumn{2}{c}{ Germination (\%) } & \multicolumn{2}{c}{$\begin{array}{c}\text { Fresh } \\
\text { Weight (g) }\end{array}$} & \multicolumn{2}{c}{$\begin{array}{c}\text { Germination } \\
\text { Rate (\%) }\end{array}$} & $\begin{array}{c}\text { Fresh } \\
\text { Weight Rate (\%) }\end{array}$ \\
\cline { 3 - 9 } & & Average & SD $^{\mathbf{1}}$ & Average & SD & Endpoint & Average \\
\hline Barley & 25 & 97.00 & 2.08 & 26.75 & 0.55 & 98.32 & 98.29 \\
Barley & 50 & 98.33 & 1.73 & 26.34 & 0.52 & 100.68 & 100.30 \\
Cress & 25 & 77.23 & 2.00 & 5.60 & 0.18 & 97.59 & 98.96 \\
Cress & 50 & 79.67 & 3.06 & 5.11 & 0.20 & 100.00 & 96.40 \\
\hline
\end{tabular}

${ }^{1}$ Standard deviation.

Table 22 depicts the results related to the validity criteria (control soil) described in Section 2.7.4. The control cultures passed all the evaluation criteria (germination over 70\%, surviving rate over $90 \%$ and no phytotoxic effects observed). Therefore, the results were considered valid.

Table 22. Validity criteria of germinated plants and fresh biomass (with control soil).

\begin{tabular}{ccccc}
\hline Plant & $\begin{array}{c}\text { Control Soil } \\
\text { Concentration } \\
\mathbf{( \% )}\end{array}$ & $\begin{array}{c}\text { Germination } \\
\mathbf{( \% )}(\mathbf{7 0 \% )}\end{array}$ & $\begin{array}{c}\text { Surviving Rate (\%) } \\
\mathbf{( > 9 0 \% )}\end{array}$ & $\begin{array}{c}\text { Phytotoxic } \\
\text { Effects (None) }\end{array}$ \\
\hline Barley & 25 & 98.66 & 100.00 & None \\
Barley & 50 & 97.67 & 100.00 & None \\
Cress & 25 & 79.14 & 97.19 & None \\
Cress & 50 & 79.67 & 95.92 & None \\
\hline
\end{tabular}

No significant differences in the germination and biomass production were observed between the control and test material. Therefore, the 3rd generation bags did not show any phytotoxic/ecotoxic effect. 


\section{Conclusions}

This work has developed, after the improvement of successive generations of compounds and biofilms, a biodegradable protective bag for banana bunches with $92.5 \mathrm{wt} \%$ of Mater-Bi biopolymer, $2.5 \mathrm{wt} \%$ of $\mathrm{TiO}_{2}$ (for ultraviolet light filtration), and reinforced with $5 \mathrm{wt} \%$ banana fiber obtained from the pseudostem waste of banana plants. The process parameters for compounding extrusion and blown film extrusion were adjusted to be able to produce the final bags, which demonstrated to be functional and biodegradable.

Among the biopolymers tested, Mater-Bi obtained the best results in the validation in field, mainly due to its lower stiffness, being within the range of LDPE used for conventional non-biodegradable bags. Regarding the fiber content and processing, a maximum of $5 \%$ fiber content was able to be industrially processed by compounding extrusion and blown film extrusion (for higher contents, the extruded thread in the compounding extrusion was very stiff and broke frequently, while in the blown film extrusion, holes frequently appeared during the blowing). Additionally, the combing process implemented in the fiber extraction machine demonstrated to provide the enough cleanliness/purity to the fiber to improve the mechanical properties on the compound and reduce the fiber degradation during the compounding and blown film extrusions. This allowed the elimination of the $\mathrm{NaOH}$ treatment, consequently improving the sustainability of the process. Moreover, the sieving process was important to eliminate impurities that may also degrade, and to remove fibers longer than $2 \mathrm{~mm}$ that may hinder the processability.

The micronizing step applied to the compounding materials allowed the reduction of the fiber length, thus improving the film-blowing process and, consequently, reducing the thickness of the film (less material and more flexible bags compared to the non-micronized ones). Additionally, the validation in field demonstrated that the micronizing was crucial to improve the contact between bags and fruit (smoother bags that led to lower friction with the fruit), thus avoiding the appearance of scratches on the bananas. Apart from this, the final bags reduced the maturation process between 1 and 2 weeks compared to the standard bags. Moreover, they were easier to put them on due to the higher consistency provided by the banana fiber. Despite this higher stiffness compared to the standard ones, the final bags were flexible enough to be easily knotted to the stem of the bunch. The only disadvantage observed was the low transparency, which hinders the visual check by farmers for the harvest and pest control.

The final bags can also be certified as biodegradable since they have a biodegradability higher than $90 \%$, meet the European content limits of heavy metals and other substances after biodegradation, and do not produce toxic effects on soil for future crops. This property, together with the use of banana fiber, make these bags a key aspect for the circular economy of waste from banana crops in the Canary Islands.

Apart from this specific application, banana fiber has a great potential for its use not only as a reinforcement, but also as a component of biocomposites that can be reincorporated into the productive cycle from which it comes. Therefore, this work could serve as a reference for other applications of this waste in the search of more environmentally friendly products and processes in the agriculture sector.

Author Contributions: Conceptualization, P.B., R.P., M.M. and L.G.; methodology, M.M., L.G., R.P. and P.B.; software, G.V. and C.P.; validation, P.B., R.P., C.P., G.V., M.M. and L.G.; formal analysis, C.P. and L.G.; investigation, P.B., R.P., C.P., G.V., M.M. and L.G.; resources, M.M. and L.G.; data curation, G.V. and C.P.; writing - original draft preparation, P.B., R.P., M.M. and G.V.; writing-review and editing, P.B., R.P., G.V. and M.M.; visualization, P.B., R.P., C.P. and G.V.; supervision, M.M. and L.G.; project administration, M.M. and L.G.; funding acquisition, M.M. and L.G. All authors have read and agreed to the published version of the manuscript.

Funding: This research was funded by the Environment and Climate Action LIFE Programme (European Union), as research was conducted under the LIFEBAQUA project (code: LIFE15 ENV/ES/000157).

Data Availability Statement: Data is contained within the article.

Conflicts of Interest: The authors declare no conflict of interest. 


\section{References}

1. European Commission. Circular Economy Action Plan. In For a Cleaner and More Competitive Europe; European Commission: Brussels, Belgium, 2020.

2. Bourguignon, D. Closing the Loop. New Circular Economy Package; European Union: Brussels, Belgium, 2016.

3. Borrello, M.; Lombardi, A.; Pascucci, S.; Cembalo, L. The Seven Challenges for Transitioning into a Bio-based Circular Economy in the Agri-food Sector. Recent Patents Food Nutr. Agric. 2016, 8, 39-47. [CrossRef] [PubMed]

4. Suffo, M.; De La Mata, M.; Molina, S. A sugar-beet waste based thermoplastic agro-composite as substitute for raw materials. J. Clean. Prod. 2020, 257, 120382. [CrossRef]

5. Lucarini, M.; Durazzo, A.; Romani, A.; Campo, M.; Boccia, G.L.; Cecchini, F. Bio-Based Compounds from Grape Seeds: A Biorefinery Approach. Molecules 2018, 23, 1888. [CrossRef] [PubMed]

6. Chiellini, E.; Cinelli, P.; Imam, S.H.; Mao, L. Composite Films Based on Biorelated Agro-Industrial Waste and Poly(vinyl alcohol). Preparation and Mechanical Properties Characterization. Biomacromolecules 2001, 2, 1029-1037. [CrossRef] [PubMed]

7. Nair, K.M.; Thomas, S.; Groeninckx, G. Thermal and dynamic mechanical analysis of polystyrene composites reinforced with short sisal fibres. Compos. Sci. Technol. 2001, 61, 2519-2529. [CrossRef]

8. Bakare, I.; Okieimen, F.; Pavithran, C.; Khalil, H.A.; Brahmakumar, M. Mechanical and thermal properties of sisal fiber-reinforced rubber seed oil-based polyurethane composites. Mater. Des. 2010, 31, 4274-4280. [CrossRef]

9. Zhu, Z.; Wu, H.; Ye, C.; Fu, W. Enhancement on Mechanical and Thermal Properties of PLA Biocomposites Due to the Addition of Hybrid Sisal Fibers. J. Nat. Fibers 2017, 14, 875-886. [CrossRef]

10. Nayak, S.K.; Mohanty, S. Sisal Glass Fiber Reinforced PP Hybrid Composites: Effect of MAPP on the Dynamic Mechanical and Thermal Properties. J. Reinf. Plast. Compos. 2009, 29, 1551-1568. [CrossRef]

11. Idicula, M.; Neelakantan, N.R.; Oommen, Z.; Joseph, K.; Thomas, S. A study of the mechanical properties of randomly oriented short banana and sisal hybrid fiber reinforced polyester composites. J. Appl. Polym. Sci. 2005, 96, 1699-1709. [CrossRef]

12. Głowińska, E.; Datta, J.; Parcheta, P. Effect of sisal fiber filler on thermal properties of bio-based polyurethane composites. J. Therm. Anal. Calorim. 2017, 130, 113-122. [CrossRef]

13. Ramnath, B.V.; Manickavasagam, V.; Elanchezhian, C.; Krishna, C.V.; Karthik, S.; Saravanan, K. Determination of mechanical properties of intra-layer abaca-jute-glass fiber reinforced composite. Mater. Des. 2014, 60, 643-652. [CrossRef]

14. Ramnath, B.V.; Kokan, S.J.; Raja, R.N.; Sathyanarayanan, R.; Elanchezhian, C.; Prasad, A.R.; Manickavasagam, V. Evaluation of mechanical properties of abaca-jute-glass fibre reinforced epoxy composite. Mater. Des. 2013, 51, 357-366. [CrossRef]

15. Ramana, M.V.; Ramprasad, S. Experimental Investigation on Jute/Carbon Fibre Reinforced Epoxy Based Hybrid Composites. Mater. Today Proc. 2017, 4, 8654-8664. [CrossRef]

16. Kureemun, U.; Ravandi, M.; Tran, L.; Teo, W.; Tay, T.; Lee, H. Effects of hybridization and hybrid fibre dispersion on the mechanical properties of woven flax-carbon epoxy at low carbon fibre volume fractions. Compos. Part B Eng. 2018, 134, 28-38. [CrossRef]

17. Akil, H.M.; Santulli, C.; Sarasini, F.; Tirillò, J.; Valente, T. Environmental effects on the mechanical behaviour of pultruded jute/glass fibre-reinforced polyester hybrid composites. Compos. Sci. Technol. 2014, 94, 62-70. [CrossRef]

18. Jeencham, R.; Suppakarn, N.; Jarukumjorn, K. Effect of flame retardants on flame retardant, mechanical, and thermal properties of sisal fiber/polypropylene composites. Compos. Part B Eng. 2014, 56, 249-253. [CrossRef]

19. Dunne, R.K.; Desai, D.; Sadiku, R. Material characterization of blended sisal-kenaf composites with an ABS matrix. Appl. Acoust. 2017, 125, 184-193. [CrossRef]

20. Xia, C.; Shi, S.Q.; Wu, Y.; Cai, L. High pressure-assisted magnesium carbonate impregnated natural fiber-reinforced composites. Ind. Crop. Prod. 2016, 86, 16-22. [CrossRef]

21. Xia, C.; Wang, K.; Dong, Y.; Zhang, S.; Shi, S.Q.; Cai, L.; Ren, H.; Zhang, H.; Li, J. Dual-functional natural-fiber reinforced composites by incorporating magnetite. Compos. Part B Eng. 2016, 93, 221-228. [CrossRef]

22. Kusić, D.; Božič, U.; Monzón, M.D.; Paz, R.; Bordón, P. Thermal and Mechanical Characterization of Banana Fiber Reinforced Composites for Its Application in Injection Molding. Materials 2020, 13, 3581. [CrossRef]

23. Amir, N.; Abidin, K.A.Z.; Shiri, F.B.M. Effects of Fibre Configuration on Mechanical Properties of Banana Fi-bre/PP/MAPP Natural Fibre Reinforced Polymer Composite. Procedia Eng. 2017, 184, 573-580. [CrossRef]

24. Arthanarieswaran, V.; Kumaravel, A.; Kathirselvam, M. Evaluation of mechanical properties of banana and sisal fiber reinforced epoxy composites: Influence of glass fiber hybridization. Mater. Des. 2014, 64, 194-202. [CrossRef]

25. European Bioplastics. Global Production Capacities of Bioplastics: Bioplastic Marked Data 2016; European Bioplastics: Berlin, Germany, 2016.

26. Dreizen, C. 2020 Bioplastics Market Forecast; Markets and Markets Research Private Ltd.: Northbrook, IL, USA, 2017.

27. European Commission. DG ENV Plastic Waste in the Environment-Final Report; European Commission: Brussels, Belgium, 2011.

28. European Commision. Questions and Answers on the Proposal to Reduce the Consumption of Plastic Bags; European Commission: Brussels, Belgium, 2013.

29. Wang, X.; Tang, Y.; Zhu, X.; Zhou, Y.; Hong, X. Preparation and characterization of polylactic acid/polyaniline/nanocrystalline cellulose nanocomposite films. Int. J. Biol. Macromol. 2020, 146, 1069-1075. [CrossRef] [PubMed]

30. Perumal, A.B.; Sellamuthu, P.S.; Nambiar, R.B.; Sadiku, E.R. Development of polyvinyl alcohol/chitosan bio-nanocomposite films reinforced with cellulose nanocrystals isolated from rice straw. Appl. Surf. Sci. 2018, 449, 591-602. [CrossRef] 
31. Yang, W.; Weng, Y.-X.; Puglia, D.; Qi, G.; Dong, W.; Kenny, J.M.; Ma, P. Poly(lactic acid)/lignin films with enhanced toughness and anti-oxidation performance for active food packaging. Int. J. Biol. Macromol. 2020, 144, 102-110. [CrossRef]

32. Varghese, S.A.; Pulikkalparambil, H.; Rangappa, S.M.; Siengchin, S.; Parameswaranpillai, J. Novel biodegradable polymer films based on poly(3-hydroxybutyrate-co-3-hydroxyvalerate) and Ceiba pentandra natural fibers for packaging applications. Food Packag. Shelf Life 2020, 25, 100538. [CrossRef]

33. Berthet, M.-A.; Angelliercoussy, H.; Chea, V.; Guillard, V.; Gastaldi, E.; Gontard, N. Sustainable food packaging: Valorising wheat straw fibres for tuning PHBV-based composites properties. Compos. Part A Appl. Sci. Manuf. 2015, 72, 139-147. [CrossRef]

34. Cunha, M.; Berthet, M.-A.; Pereira, R.; Covas, J.A.; Vicente, A.A.; Hilliou, L. Development of polyhydroxyalkanoate/beer spent grain fibers composites for film blowing applications. Polym. Compos. 2015, 36, 1859-1865. [CrossRef]

35. Kharrat, F.; Khlif, M.; Hilliou, L.; Haboussi, M.; Covas, J.; Nouri, H.; Bradai, C. Minimally processed date palm (Phoenix dactylifera L.) leaves as natural fillers and processing aids in poly(lactic acid) composites designed for the extrusion film blowing of thin packages. Ind. Crop. Prod. 2020, 154, 112637. [CrossRef]

36. Srivastava, K.; Singh, M.K.; Mishra, P.K.; Srivastava, P. Pretreatment of banana pseudostem fibre for green composite packaging film preparation with polyvinyl alcohol. J. Polym. Res. 2019, 26, 95. [CrossRef]

37. ASPROCAN. Dosier_Estadisticas_Asprocan_2019; ASPROCAN: Santa Cruz de Tenerife, Spain, 2019.

38. DuPontTM. Polymers, Light and the Science of $\mathrm{TiO}^{2}$; DuPontTM: Wilmington, DE, USA, 2007.

39. LIFE Multibiosol. Available online: https://multibiosol.eu/ (accessed on 8 January 2021).

40. Paz, R.; Monzón, M.; Vega, G.; Díaz, N.; Pestana, D. Use of Banana Crop Wastes to Develop Products in the Aquaculture and Plastic Sectors. In Agricultural, Forestry and Bioindustry Biotechnology and Biodiscovery; Springer Nature: Berlin/Heidelberg, Germany, 2020; pp. 259-270.

41. Vega Rodríguez, G.; Monzón, M.; Díaz Padilla, N.; Paz Hernández, R. Pilot Plant for the New Use of a Waste of Banana Crop to Develop Products of Plastic Composite and Aquaculture. In Proceedings of the Materials E Nanomaterials. An International Conference, Paris, France, 17-19 July 2019; Sciknowledge: Badajoz, Spain, 2019.

42. Ortega, Z.; Monzón, M.D.; Benítez, A.N.; Kearns, M.; McCourt, M.; Hornsby, P.R. Banana and Abaca Fiber-Reinforced Plastic Composites Obtained by Rotational Molding Process. Mater. Manuf. Process. 2013, 28, 130614085148001. [CrossRef]

43. Benítez, A.; Monzón, M.; Angulo, I.; Ortega, Z.; Hernández, P.; Marrero, M. Treatment of banana fiber for use in the reinforcement of polymeric matrices. Measurement 2013, 46, 1065-1073. [CrossRef]

44. Díaz, N.; Ortega, R.; Monzón, M.D.; Pestana, D.; Paz, R. Pilot Plant for Alkali Treatment of Chopped Banana Fibre. In Proceedings of the 4th International Conference on Green Chemistry and Sustainable Engineering (GreenChem-18), Madrid, Spain, 23-25 July 2018; Royal Society of Chemistry: Cambridge, UK, 2018.

45. Overview of Materials for Low Density Polyethylene (LDPE), Blow Molding Grade. Available online: http:/ /www.matweb.com/ search/datasheet_print.aspx?matguid=b34a78d271064c4f85f28a9ffaf94045 (accessed on 8 January 2021). 